\title{
Anaerobic conditions unmask antimicrobial resistance
}

A. Creasy-Marrazzo ${ }^{1 \dagger}$, M.M. Saber ${ }^{2 \dagger}$, M. Kamat ${ }^{3}$, L. S. Bailey ${ }^{3}$, F. Qadri ${ }^{4}$, K. B. Basso ${ }^{3}$, B. J. Shapiro², E. J. Nelson ${ }^{1 *}$

${ }^{1}$ Departments of Pediatrics and Environmental and Global Health, University of Florida, Gainesville, FL, USA,

${ }^{2}$ Department of Microbiology \& Immunology, McGill University

${ }^{3}$ Departments of Chemistry, University of Florida, Gainesville, FL, USA,

${ }^{4}$ Infectious Diseases Division (IDD) \& Nutrition and Clinical Services Division (NCSD), International Centre for Diarrhoeal Disease Research, Bangladesh (ICDDR,B), Dhaka, Bangladesh

${ }^{\dagger}$ Co-first authors

* Corresponding author

Keywords: Antimicrobial resistance, AMR, antibiotics, cholera, diarrhoea, diarrhea,

Vibrio cholerae, enteropathogens, Bangladesh, anaerobic, anoxic, hypoxic, respiration 


\section{Abstract}

2 Antimicrobial resistance (AMR) in Gram negative enteropathogens is an urgent threat to

3 the antibiotic formulary. These taxa undergo anaerobic respiration within the host, yet

4 little is known about how anaerobic conditions influence antimicrobial resistance (AMR).

5 The facultative enteropathogen Vibrio cholerae was chosen as a model to determine the

6 impact of anaerobic growth on AMR because cholera is one of the few non-invasive

7 diarrhoeal diseases for which antibiotics are indicated, albeit conditionally. V. cholerae

8 isolates from a single outbreak were tested for resistance by minimal inhibitory

9 concentrations (MIC) under aerobic and anaerobic conditions against clinically relevant antibiotics. Here we show that the odds of classifying isolates as resistant under

11 anaerobic compared to aerobic conditions increased over 20 times for ciprofloxacin and

1250 times for azithromycin, yet for doxycycline, all isolates remained below the

13 breakpoint for resistance. Genome-wide association studies (GWAS) found significant

14 associations between known and unknown genetic elements and AMR phenotypes that

15 varied by oxygen exposure and antibiotic concentrations. In most cases, AMR phenotypes were more heritable - and more genes significantly associated with AMR

17 were discovered - under anaerobic conditions compared to aerobic conditions. These

18 findings challenge the paradigm of testing facultative enteropathogens for AMR under aerobic conditions alone. This experimental approach establishes a new, more sensitive

20 framework to track and investigate mechanisms of AMR. 


\section{INTRODUCTION}

Antimicrobial resistance (AMR) in Gram negative pathogens arises by point mutation(s) and AMR gene acquisition and is selected by high rates of inappropriate antibiotic use. Fast and accurate approaches to identify AMR are needed to gauge the extent to which the antibiotic formulary is threatened. However, knowledge gaps remain on the factors and mechanisms that result in AMR. There are also debates surrounding how well conventional in vitro assays represent in vivo physiology. For example, facultative anaerobic pathogens experience hypoxia and anoxia within the gastrointestinal tract ${ }^{1,2}$, yet standard in vitro assays test for AMR under aerobic conditions alone ${ }^{3}$. How a factor as fundamental as oxygen exposure effects AMR is poorly understood. To investigate this question, we chose the facultative anaerobe Vibrio cholerae as a model system. In V. cholerae mechanisms of AMR and anaerobic growth are well characterized in vivo and in vitro ${ }^{4-11}$, and cholera is one of the few non-invasive diarrhoeal diseases for which antibiotics are indicated, albeit conditionally.

Rehydration is the definitive intervention for acute diarrhoeal disease ${ }^{12}$. Antibiotics are supportive and indicated for only a few diarrhoeal diseases, including cholera ${ }^{13,14}$. The World Health Organization (WHO) recommends ciprofloxacin, azithromycin or doxycycline for cholera patients with severe dehydration ${ }^{12,14-16}$. Antibiotics shorten the frequency and duration of diarrhoea ${ }^{16}$. In practice, guideline adherence in cholera endemic regions may be low out of clinical concern that a patient 'might have cholera' and that the patient may develop severe dehydration, contributing to rates of inappropriate antibiotic usage that can rise above $90 \%{ }^{17,18}$. Strong regional associations between antibiotic use and rise of AMR have been observed across enteric taxa, 
44 including V. cholerae ${ }^{19-21}$. Given that AMR genetic elements frequently co-localize on

45 mobile elements ${ }^{22}$, inappropriate single-agent therapy poses a risk of multidrugresistance (MDR) selection.

47

Associations between AMR phenotypes and genotypes are well known for the three antibiotics recommended to treat cholera; the cognate AMR mechanisms share commonality across Gram negative taxa. Ciprofloxacin (a fluoroquinolone) resistance mechanisms include mutations in genes encoding type II topoisomerases (e.g. gyrA, gyrB, parC, parE $)^{23,24}$. Synergy occurs such that mutations in gyrA and parC increase ciprofloxacin resistance 60-fold, but the individual effects are 10- to 16-fold and 0-fold, respectively ${ }^{23,25-28}$. Efflux pump upregulation, porin loss and Qnr expression also convey fluoroquinolone resistance 23,24 . Resistance can increase over 30 -fold when strains harbor qnr family genes ${ }^{23,29,30}$. In V. cholerae, qnrv.cholerae resides on an integrative and

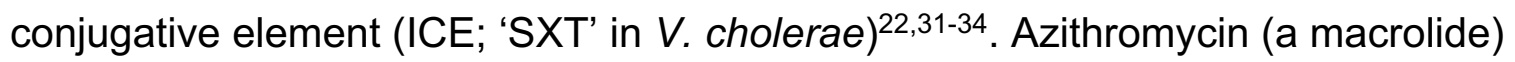
resistance mechanisms are similarly diverse and include mutations in the 23S ribosomal RNA (rRNA) target genes and ribosomal protein genes. Macrolide resistance is also conveyed by carriage of rRNA methyltransferase genes (erm) and associated induction mechanisms, cis-acting peptides, efflux systems (e.g. mef, msr), macrolide esterases (e.g. ere), and macrolide phosphotransferases (e.g. mphA, which often resides in the $V$. cholerae SXT element) ${ }^{35}$. Doxycycline (a tetracycline) resistance is conferred by mutations in the $16 \mathrm{~S}$ rRNA component of the $30 \mathrm{~S}$ ribosomal subunit ${ }^{36}$. Additional mechanisms include tetracycline-specific ribosomal protection proteins (RPPs), tetracycline specific efflux pumps (e.g. tet(59)) that can reside on SXT element in $V$. 
cholerae, intrinsic efflux pumps, AraC-transcriptional activators, and cytoplasmic ATP-

67 dependent serine proteases ${ }^{36}$.

Complex associations between AMR phenotypes and genotypes have been studied by random mutagenesis, phenotypic screening, and network analyses ${ }^{37-42}$, and applied in V. cholerae ${ }^{43}$. These studies uncovered how the effect of an antibiotic is shaped by a large number of often more subtle physiologic perturbations, including altered DNA synthesis/repair, central metabolism/growth, and SOS response ${ }^{44-46}$. A limitation of AMR assays conducted under aerobic conditions alone is that they may not reflect these physiologic perturbations experienced in the host. Aerobic oxidative phosphorylation generates reactive oxygen species (ROS) that are lethal unless a sufficient defense is mounted by factors like superoxide dismutase, catalase, and glutathione systems ${ }^{47,48}$. Under anaerobic conditions, growth rate typically slows and proton motive force is reduced $^{49,50}$, which can have both synergistic and antagonistic effects on antibiotics 46,51. In Escherichia coli, ROS are generated after fluroquinolone (bactericidal) treatment under aerobic conditions ${ }^{52}$ and fluoroquinolone tolerance increases under anaerobic conditions $^{53-55}$. The extent to which tetracyclines and macrolides (both bacteriostatic) induce ROS and how anaerobiosis influences tolerance is less known ${ }^{44,56,57 .}$

The objective of this study was to compare AMR phenotypes with underlying genotypes under aerobic and anaerobic conditions. We hypothesized that rates of AMR would differ between aerobic and anaerobic conditions, and that distinct genetic elements would be associated with phenotypes under the different conditions. To test these two hypotheses, $V$. cholerae isolates were collected from cholera patients ${ }^{58}$. We found that phenotypic resistance to ciprofloxacin and azithromycin, but not to doxycycline, 
increased significantly under anaerobic conditions. Testing under anaerobic conditions also allowed us to discover novel genes associated with AMR. Taken together, our results show how the genetic basis of AMR differs between aerobic and anaerobic conditions, with implications for AMR surveillance in public health, research and clinical settings.

\section{METHODS}

Clinical sample collection. The clinical samples in this study were collected as part of a previously published IRB approved study ${ }^{58}$. Recruitment, consent, enrollment and procedures have been described previously ${ }^{58}$. In brief, stool samples were obtained during the spring cholera outbreak period of 2006 at the International Centre for Diarrhoeal Disease Research, Bangladesh (icddr,b) in Dhaka, Bangladesh. Samples were collected prior to hospital administration of antibiotics; patient histories were negative for known antibiotic exposure. The library consists of $67 \mathrm{~V}$. cholerae isolates (Supplementary Table 1). Paired stool supernatant was available for 50 isolates.

Antimicrobial resistance testing. Growth kinetics and MIC determinations for ciprofloxacin, azithromycin, and doxycycline were performed in LB broth with twelve two-fold serial dilutions with concentrations approximated for CLSI MIC breakpoints $^{3}$ for V. cholerae (ciprofloxacin $=2 \mu \mathrm{g} / \mathrm{ml}$; azithromycin $=4 \mu \mathrm{g} / \mathrm{ml}$; doxycycline $=16 \mu \mathrm{g} / \mathrm{ml})^{3}$. Isolates were prepared and grown aerobically at $37^{\circ} \mathrm{C}$ in $15-\mathrm{ml}$ tubes containing $5-\mathrm{ml} \mathrm{LB}$ broth at 220 r.p.m. Bacteria were back-diluted to a final $\mathrm{OD}_{600}$ of $0.01(200 \mu \mathrm{l} /$ well) in LB with or without the respective antibiotic dilution-series in black Corning CoStar clearbottom 96-well plates. Plates were placed in a BioTek Synergy H1 reader pre-warmed 
111 to $37^{\circ} \mathrm{C}$ with the lid on. Anaerobic conditions were generated using a continuous

112 chamber flow $\left(5 \% \mathrm{CO}_{2}, 95 \% \mathrm{~N}_{2}\right)$ and a BioTek $\mathrm{CO}_{2} / \mathrm{O}_{2}$ gas controller; anaerobic growth

113 plates were given a 10-minute equilibration period. $\mathrm{OD}_{600}$ was measured every 2

114 minutes for 8 hours at $37^{\circ} \mathrm{C}$ with orbital shaking at 220 r.p.m. A standard logistic

115 equation was fit to growth curve data using the $\mathrm{R}$ package growthcurver version $0.3 .0^{59}$.

116 Outcome measures were generation time, carrying capacity (k), and area under the

117 curve (AUC). The MIC was determined using a logistic fit for growth over the twelve,

118 two-fold serial dilutions of the test antibiotic. Binary phenotypic resistance categories

119 were set in concordance with CLSI standards. Intermediate and resistant isolates were

120 scored as resistant

121

122

123

124

125

126

127

128

129

130 131 protection by catalase (data not shown).

132 Whole-genome sequencing. Genomic DNA was extracted from V. cholerae isolates

Use of catalase to determine if ROSs contribute to antibiotic sensitivity. To test if the reduction of reactive oxygen species (ROSs) was associated with increased tolerance to antibiotics under aerobic conditions, MICs were determined for two select strains (E7946, EN160) with/without catalase added to the media (10 U/ml). Catalase quenches $\mathrm{H}_{2} \mathrm{O}_{2}$ that freely diffuses across the cell envelope. Controls consisted of adding $10 \mathrm{mM} \mathrm{H}_{2} \mathrm{O}_{2}$ to media with catalase, bacteria, or catalase and bacteria. The catalase and $\mathrm{H}_{2} \mathrm{O}_{2}$ concentrations were chosen based on optimization experiments in which $V$. cholerae were cultured with a gradient of catalase $(0,0.001,0.01,0.1,1,10$ $\mathrm{U} / \mathrm{ml})$ and a gradient $\mathrm{H}_{2} \mathrm{O}_{2}(0,0.1,1,10 \mathrm{mM})$. Growth curves were performed with viable counts as endpoints to determine the minimum dose for lethality by $\mathrm{H}_{2} \mathrm{O}_{2}$ or using the Qiagen DNeasy Blood and Tissue Kit. Library construction was completed 
134 using the Illumina Nextera XT v.2 DNA Library Preparation Kit. Twenty-four genomes were pooled and sequenced on an Illumina MiSeq for 500 cycles per run. Using CLC Genomics Workbench v20, raw reads were filtered by length, trimmed, and mapped to

137 the reference genome ( $V$. cholerae O1 El Tor E7946) to identify single-nucleotide variants. To identify genes not present in the reference genome, contigs were assembled de novo using CLC Genomics Workbench v20. Known resistance genes were identified using the comprehensive antibiotic resistance database (CARD) ${ }^{60,61}$ and

141 ResFinder $62,63$.

142 Genome-wide association studies. A series of genome-wide association studies

143 (GWAS) were conducted to detect genomic variants associated with antibiotic resistance phenotypes under both aerobic and anaerobic conditions; a total of 30

145 GWAS were generated by 3 antibiotics $x 5$ antibiotic concentrations $x 2$ oxygen conditions. The sample size for analysis was 67 genomes. To extract genomic variants,

147 which can potentially capture all sources of variation in the genome (i.e single 148 nucleotide variants, indels and gene presence/absence) without a priori assumption 149 about the underlying gene content of each sample (e.g. accessory genes or plasmids), unitigs were generated from genomes assembled using GATB ${ }^{64}$. Unitigs are sequences

151 of variable length (unlike k-mers of fixed length $k$ ) which represent the variations in the 152 population of genomes under study in high-resolution. GWAS were performed using 153 linear mixed models implemented in pyseer v.1.3.6 and adjusted for population 154 stratification using the kinship matrix estimated from the phylogenetic tree ${ }^{65}$.

155 To generate the phylogenetic tree, genome alignments consisting entirely of variable nucleotides were produced from whole genome SNP data generated by CLC Genomics 
157 Workbench v20 using VCF-kit $0.1 .6^{66}$. The tree was then inferred by RaxML under the general time reversible (GTR) model with rate variation across sites following a GAMMA distribution $^{67}$. We used the linear-mixed model approach to adjust for population stratification and linkage disequilibrium in microbial GWAS ${ }^{68}$. Heritability $\left(\mathrm{h}^{2}\right)$, an estimate of the proportion of the phenotype variance that can be explained by total genomic variation represented in the unitigs, was also calculated using pyseer v.1.3.6. Likelihood-ratio test $p$-values for the association tests were adjusted for multiple-testing by Bonferroni correction (at a genome-wide false discovery rate of 0.05 ) for the number of unique unitig patterns (i.e. only giving one count to a unitig with an identical presence/absence profile across genomes). We also removed unitigs tagged with the errors 'bad-chisq', 'pre-filtering-failed', 'Irt-filtering-failed', 'firth-fail' and 'matrixinversionerror' after the analysis. To further remove false positive GWAS hits, we removed any considerable clusters of unitigs $(>20)$ with identical $p$-values, as these are likely to be lineage-specific markers or markers with strong linkage disequilibrium

171 comprised of mostly non-causal variants linked on the same clonal frame. GWAS hits were annotated by mapping the unitigs to two reference genomes of $V$. cholerae, namely, E7946 (NCBI assembly accession number: GCA_002749635.1) and O1

174 biotype El Tor strain N16961 (NCBI assembly accession number: GCA_003063785.1) 175 using BWA. Statistically significant GWAS hits were further annotated with the CARD 176 resistance gene identifier (RGI) after filtering the 'loose' hits and hits with identity $<0.90$.

177 Antibiotic detection by liquid chromatography mass spectrometry (LC-MS/MS).

178 This approach was based on former studies ${ }^{69}$. Stool supernatants were centrifuged and 179 filtered (0.2 $\mathrm{MM}$ surfactant-free cellulose acetate; Thermo Scientific Nalgene). Proteins 
were precipitated (1:7 ratio $(\mathrm{v} / \mathrm{v})$ of water::methanol). Supernatants were diluted with methanol and water $(1: 1 \mathrm{v} / \mathrm{v})$ in $0.1 \%$ formic acid for liquid chromatography, and $5 \mu \mathrm{l}$ of supernatant was injected for analysis. LC/MSMS was performed on a $2.1 \times 150-\mathrm{mm}$ Hypersil Gold aQ column (particle size, $3 \mu \mathrm{m}$ ) using a high-performance liquid chromatography system (Thermo UltiMate 3000 series) with an LTQ XL ion trap mass spectrometer (Thermo Fisher Scientific). Mobile phases were 1\% formic acid in water (A) and $1 \%$ formic acid in methanol (B) and held at a constant $5 \% \mathrm{~B}$ for $2 \mathrm{~min}$ before ramping to $95 \% \mathrm{~B}$ at 15 min where it was held for an additional minute before returning to starting conditions for a total run time of $25 \mathrm{~min}$.

Eluent was ionized using electrospray ionization (ESI) in positive mode at a spray voltage of $5 \mathrm{kV}$, a nitrogen sheath gas flow rate of $8 \mathrm{~L} \mathrm{~min}^{-1}$, and capillary temperature of $300^{\circ} \mathrm{C}$. Two scan events were programmed to perform an initial scan from $\mathrm{m} / \mathrm{z} 100$ to 1000 , which was followed by targeted collision induced dissociation based on a retention time and mass list. Retention time windows ranged from 0.35 minutes to 6.50 min, depending on the elution range of the standards at high and low concentrations. Masses were targeted for the most abundant adduct or ion associated with each antibiotic (typically the $[\mathrm{M}+\mathrm{H}]^{+}$ion) with a $\mathrm{m} / \mathrm{z} 1$ window. Data analysis for the amoxicillin, sulfamethoxazole/trimethoprim, azithromycin, tetracycline, doxycycline, metronidazole, nalidixic acid, and ciprofloxacin was performed manually using extracted ion chromatograms and MSMS matching with an in-house antibiotic MSMS library using Xcalibur 2.2 SP 1.48 (Thermo Fisher Scientific). 
201 Statistical analysis. Bivariate analyses of categorical data were analyzed using

202 Fisher's Exact Test, and continuous data were analyzed using the Mann-Whitney U

203 Test (alpha $=0.05)$. McNemar's test was used to analyze paired data (alpha $=0.05)$.

\section{RESULTS}

Comparison of antimicrobial resistance under aerobic and anaerobic conditions.

206 Pairwise analysis for baseline growth parameters found that carrying capacity, AUC,

207 and growth velocity were significantly lower under anaerobic compared to aerobic

208 conditions (Supplementary Table 2). In this physiologic context, the distribution of

209 resistance differed depending on aerobic versus anaerobic conditions (Fig. 1). The MIC

210 modes for ciprofloxacin were $7 \mu \mathrm{g} / \mathrm{ml}(\min =0.0016 \mu \mathrm{g} / \mathrm{ml} ; \max =32 \mu \mathrm{g} / \mathrm{ml})$ and $2 \mu \mathrm{g} / \mathrm{ml}$

$211(\min =0.004 \mu \mathrm{g} / \mathrm{ml} ; \max =8 \mu \mathrm{g} / \mathrm{ml})$ under anaerobic and aerobic conditions, respectively

212 (Supplementary Table 3). The rates of resistance under anaerobic $(93 \% ; N=62 / 67)$ and

213 aerobic (54\%; N=36/67) conditions were significantly different (Fig. 1a; Supplementary

214 Table 4). For azithromycin, the MIC modes were $32 \mu \mathrm{g} / \mathrm{ml}(\min =8 \mu \mathrm{g} / \mathrm{ml}$; $\max =128$

$215 \mu \mathrm{g} / \mathrm{ml})$ and $4 \mu \mathrm{g} / \mathrm{ml}(\min =1 \mu \mathrm{g} / \mathrm{ml}$; $\max =32 \mu \mathrm{g} / \mathrm{ml})$ under anaerobic and aerobic

216 conditions respectively (Supplementary Table 3). The rates of resistance under

217 anaerobic $(n=67 / 67 ; 100 \%)$ and aerobic $(n=15 / 67 ; 22 \%)$ conditions were significantly

218 different (Fig. 1b; Supplementary Table 4). For doxycycline, the MIC modes were 1

$219 \mu \mathrm{g} / \mathrm{ml}$ under both aerobic and anaerobic conditions, respectively (Supplementary Table

2203 3); only two isolates were found to be resistant under anaerobic conditions and one

221 under aerobic conditions. Taken together, the odds of classifying isolates as resistant

222 under anaerobic compared to aerobic conditions increased over 20 times for 
223 ciprofloxacin $(\mathrm{OR}=27 ; 95 \% \mathrm{Cl}=4.45-1105)$ and over 50 times for azithromycin $(\mathrm{OR}=$

224 53; 95\% Cl= 9.10-2134; Supplementary Table 4).

225

226

227

228

229

230

231

232

233

234

235

236

237

238

239

240

241

242

243

244

\section{Addition of catalase to test if reactive oxygen species effect antibiotic}

tolerance/sensitivity under aerobic conditions. For ciprofloxacin, the MICs for the sensitive reference strain $\mathrm{E} 7946\left(\mathrm{Cip}^{\mathrm{S}}, \mathrm{Azi}^{\mathrm{S}}\right.$, Dox $\left.{ }^{\mathrm{S}}\right)$ and the resistant clinical isolate EN160 $\left(\mathrm{Cip}^{\mathrm{R}}, \mathrm{Azi}^{\mathrm{R}}, \mathrm{Dox}{ }^{\mathrm{S}}\right)$ remained unchanged when catalase was added to the media under aerobic conditions. The addition of catalase was not associated with differences in AUCs for both E7946 and EN160 in media containing ciprofloxacin, azithromycin, or doxycycline at 2-fold below the MIC. The AUCs in LB media with and without catalase alone for E7946 and EN160 were not statistically different (Supplementary Table 5).

\section{Characterization of known AMR genetic elements under aerobic and anaerobic}

conditions. The distribution of known AMR genetic elements (Fig. 2) was grouped by

point mutations (likely transmitted vertically, not on an established mobilizable element) and horizontal transmission (on an established mobilizable element).

Point mutations in known AMR genes. For ciprofloxacin, the most identified known resistance mutations were those in the topoisomerase encoding genes gyrA (VC1258/RS06370) (Ser83lle) and parC (VC2430/RS12340) (Ser85Leu). These were present in $60 \%(40 / 67)$ and $70 \%(47 / 67)$ of all isolates, while 54\% (36/57) contained both. For azithromycin, we found no mutations in known resistance genes encoding ribosomal proteins L4 (rp/D;VC2595/RS13175) and L22 (rp/V;VC2591/RS13155) ${ }^{70,71 . ~}$ For tetracycline (proxy for doxycycline), one of the 9 total 16S rRNA genes (VCr001) was found to have a single nucleotide insertion of a $\mathrm{G}$ nucleotide at position 327 within 
245 the sequences of $15 \%(10 / 67)$ of isolates; the significance is unknown. No mutations class resistance in other Gram negative organisms ${ }^{72-74}$.

AMR genes on mobile genetic elements. The integrative conjugative element (ICE)

We examined to what extent these point mutations and genes were associated with significantly associated with qnrvc, gyrA and parC (Supplementary Table 6). with resistance under aerobic conditions alone $(P<0.001)$. The gene tet(59) was not associated with doxycycline resistance under aerobic or aerobic conditions (both $p=0.566)$.

\section{Discovery of AMR associated genetic elements under aerobic and anaerobic} conditions. To more broadly explore the genetic basis of AMR, we conducted genomewide association studies (GWAS). This approach used the phenotype of area under the

265 curve (AUC) to represent 'growth' with or without exposure to the three antibiotics at five concentrations under either aerobic or anaerobic conditions. Phenotypes (AUCs) at 
267 similar antibiotic concentrations were positively correlated within aerobic and anaerobic conditions for all three antibiotics (Fig. 3). Phenotypes were also positively correlated between aerobic and anaerobic conditions for ciprofloxacin (Fig. 3a). However, AUCs were weakly, or even negatively, correlated between aerobic and anaerobic conditions

271 for azithromycin and doxycycline (Fig. 3b,c). These results reinforce the idea that

272 anaerobic and aerobic growth are distinct under antibiotic pressure.

273 The heritability of the AMR phenotypes (AUCs) was estimated prior to the GWAS.

274 Heritability $\left(h^{2}\right)$ was defined as the proportion of phenotypic variation explained by

275 genetic variation, measured as unique contiguous tracts of the genome (unitigs) that tag both single nucleotide variants, indels, and gene content changes (Methods). We found relatively high heritability $\left(h^{2}\right.$ in the range $\left.0.60-0.99\right)$ of growth across concentrations of ciprofloxacin under both aerobic and anaerobic conditions, yielding statistically significant GWAS hits (Table 1; Supplementary Data Files). In contrast, heritability

280 tended to be much lower under aerobic compared to anaerobic conditions for both azithromycin and doxycycline, yielding significant GWAS hits only under anaerobic conditions (Table 1; Supplementary Data Files).

AMR genes identified by GWAS were diverse (Fig. 4; Supplementary Data Files). These candidates included known AMR genes, such as qnrVC and $d f r A$, which were associated with ciprofloxacin resistance under both aerobic and anaerobic conditions.

286 We identified seven genes associated with ciprofloxacin resistance under anaerobic 287 conditions alone (including the stress response gene barA and a radC homolog involved 288 in DNA repair), and ten genes under aerobic conditions alone (including rtxB). Under anaerobic conditions, most genes were identified at ciprofloxacin concentrations at or 
above $0.25 \mu \mathrm{g} / \mathrm{ml}$; however, four genes, including barA, were identified under one of the lowest tested ciprofloxacin concentrations $(0.13 \mu \mathrm{g} / \mathrm{ml})$. GWAS hits for doxycycline and azithromycin resistance were found only under anaerobic conditions. For azithromycin, two genetic elements were identified: $m p h A$ and a region between ompT and dinG (ompT-dinG). For doxycycline, 23 genes were shared across concentrations; however,

295 the gene discovery rate was highest at the lower concentrations $(\mathrm{n}=53$ at $0.13 \mu \mathrm{g} / \mathrm{ml} ; \mathrm{n}$ $296=26 \mu \mathrm{g} / \mathrm{ml})$. GWAS hits included the major facilitator superfamily antibiotic efflux pump 297 tet(59) (Fig. 4, Supplementary Data Files). The majority of genetic elements identified by GWAS for all three antibiotics have unknown function, yet the rate of detection of known AMR genes suggests that the genes of unknown function may indeed play a role in AMR.

Associations between antibiotics detected in stool by LC-MS/MS and rates of AMR at the genotypic and phenotypic levels. A total of 198 antibiotics were detected in the 51 stool supernatants tested (Fig. 5). At least one antibiotic was detected in $98 \%$ $(n=50 / 51)$, at least two antibiotics were detected in $94 \%(n=48 / 51)$, and 3 or more antibiotics were detected in $90 \%(n=46 / 51)$ of stool supernatants (Fig. 5). Antibiotics detected were ciprofloxacin ( $n=48 / 51 ; 94 \%)$, nalidixic acid $(n=41 / 51 ; 80 \%)$, metronidazole $(n=37 / 51 ; 73 \%)$, tetracycline $(n=24 / 51 ; 47 \%)$, doxycycline $(n=24 / 51$; $47 \%$ ), bactrim (sulfamethoxazole/trimethoprim; $n=22 / 51 ; 43 \%)$, and amoxicillin $(n=2 / 51$; 43\%); azithromycin was not detected. We hypothesized that resistance to ciprofloxacin, 310 azithromycin and/or doxycycline in the isolates would correlate with antibiotic detection 311 in the paired stool sample by LC-MS/MS. For quinolone/fluoroquinolone and 312 tetracycline/doxycycline, detection by LC-MS/MS was not associated with AMR 
313 genotypes or phenotypes (Supplementary Table 7). Associations for azithromycin could

314 not be tested because azithromycin was not detected.

\section{DISCUSSION}

In this study, the rate of resistance among clinical isolates differed significantly between

317 aerobic and anaerobic conditions. The extent to which isolates became tolerant to antibiotic exposure under anaerobic conditions differed by antibiotic class. The genetic basis of resistance was uniquely discoverable under anaerobic conditions and differed by antibiotic class. These findings challenge the convention of testing facultative enteropathogens for AMR under aerobic conditions alone. The approach of using AUC

322 growth curve data as a dependent continuous variable for GWAS to identify AMR genetic elements under aerobic and anaerobic conditions provides a new methodologic framework to better track AMR for clinical stewardship and public health surveillance.

Antibiotics from three disparate classes were studied. The experiments revealed commonalities as well as important difference between classes. The odds of classifying isolates as resistant under anaerobic conditions compared to aerobic conditions

328 increased over 20 times for ciprofloxacin and over 50 times for azithromycin.

329 Generalizable physiologic mechanisms for increased tolerance to antibiotics under 330 anaerobic conditions may include reduced doubling-time or growth rate limiting the 331 impact of agents that directly or indirectly disrupt cell envelope integrity. Additional

332 mechanisms include reduction in proton motive force that impacts the capacity to pump agents across the cell envelope, and ROS that induce both intracellular and cell wall

334 stress and can act synergistically to potentiate antibiotic lethality. The assays that 
335 utilized catalase to quench hydrogen peroxide were conducted to evaluate this latter possibility. The assays were limited because catalase targets one type of ROS (hydrogen peroxide) in the extracellular space, which freely diffuses from the intracellular space. For the two strains tested, the MIC for all three antibiotics did not increase with the addition of catalase suggesting that the reduction of ROSs alone

340 cannot account for increased MICs observed under anaerobic conditions

341 (Supplementary Table 5).

342 Knowledge gaps on the genetic basis of AMR have decreased dramatically with the 343 advance of whole-genome sequencing. However, this fund of knowledge is susceptible to bias because conventional methods use aerobic conditions to test for AMR among facultative enteropathogens. This study prioritized the factor of oxygen exposure as a determinant of AMR phenotype because facultative enteropathogens experience hypoxia and anoxia in the animal host. The first phase of the analysis focused on known AMR genotypes with known AMR phenotypes. For ciprofloxacin, mutations in parC and carriage of $q n r_{v_{c}}$ significantly associated with phenotypic resistance under aerobic and anaerobic conditions; mutations in gyrA significantly associated with resistant phenotypes under anaerobic conditions alone. The lack of a significant association between gyrA mutations and phenotype under aerobic conditions may be due to the

353 limited sample size. For azithromycin, $m p h A$ was identified and significantly associated 354 with AMR phenotypes under aerobic and anaerobic conditions. While tet(59) was

355 identified, very few isolates were identified as resistant to doxycycline under aerobic $356(n=1)$ or anaerobic conditions $(n=2)$. These data demonstrate that the evaluation of the relationship between of AMR genotype and phenotype may strengthen under anaerobic 
358

359

360

361

362

363

364

365

366

367

368

369

370

371

372

373

374

375

376

377

378

379

380

conditions and may expose an experimental bias in our historical understanding of AMR.

The second phase of analysis sought to identify unknown genetic elements associated with AMR. Initial attempts to use categorical data (resistant vs sensitive) in the GWAS resulted in modest gene discovery rates (data not shown). To address this problem, the continuous variable of AUC strengthened the GWAS. Breakpoint and sub-breakpoint concentrations were chosen based on a rationale that different genetic elements might contribute differently to AMR phenotypes at different antibiotic concentrations. GWAS expectedly identified $q n r_{v c}$ for ciprofloxacin exposure under aerobic and anaerobic conditions, mphA for azithromycin exposure under anaerobic conditions alone and tet(59) for doxycycline exposure under anaerobic conditions alone. For ciprofloxacin, seven genes were discovered in anaerobic conditions alone; these included a homolog for DNA repair (radC), 2-component histidine kinase involved in stress response (barA), and an ATP-dependent zinc protease. The genes dfrA31 and APH(6)-Id were identified for both aerobic and anaerobic conditions and encode a trimethoprim-resistant dihydrofolate reductase and an antibiotic inactivation protein, respectively. These genes are located on SXT with qnrvc and may therefore be associated due to genetic linkage rather than due to causal roles in ciprofloxacin resistance. For azithromycin, two genetic elements under anaerobic conditions alone were identified: $m p h A$ (mentioned above) and an intergenic region between ompT (porin; known to be associated with AMR) ${ }^{79,80}$ and dinG (ATP-dependent DNA helicase). For doxycycline, a diverse set of 57 genetic elements under anaerobic conditions alone were identified that included tet(59) (mentioned above), vexK (efflux RND transporter permease associated with AMR) ${ }^{81-83}$, 
381 and zorA (anti-phage defense system ZorAB subunit $\mathrm{A}$; a putative proton channel that may respond to membrane perturbation by depolarization $)^{84}$. autoaggregation associated factors as well as an aerotaxis protein (AerB; VC0512) ${ }^{86}$; findings consistent with roles in AMR and aerobic/ anaerobic conditions. The GWAS were limited by sample size and were at risk of increased false positive discovery rates at AMR 'hot-spots' like SXT. Despite these limitations, GWAS enabled the discovery of an intriguing list of genetic targets that were associated with AMR and require future molecular analysis to test for causal relationships. that the rates of AMR genotypes and phenotypes were higher when the stool sample contained the cognate antibiotic. A quinolone/fluoroquinolone AMR genotype (known) or phenotype was not associated with quinolone or fluoroquinolone detection. A tetracycline/doxycycline AMR genotype (known) or phenotype was not associated with tetracycline/doxycycline detection. These results were limited by a low number of control samples negative for the antibiotic in question. While antibiotics were widespread, the LC-MS/MS data cannot be used to establish prevalence because the 401 original enrollment criteria excluded patients that self-reported antibiotic intake. This 402 would seem like a significant limitation, but a prior study documented that self-reports 
study found nearly all patients shed at least one antibiotic despite self-reports of no antibiotic intake. The high detection rates of nalidixic acid detection as well as both doxycycline and tetracycline does not match clinical patterns of antibiotic prescription ${ }^{69}$. Non-medical sources of antibiotic exposure include known food and water contamination with antibiotics ${ }^{87}$. These data highlight the experimental difficulty of linking exposure to genotype and phenotype when the environment and clinical settings are nearly saturated with antibiotics. These results are a further call to action to increase antibiotic stewardship in healthcare as well as in the food-chain to combat AMR.

\section{Conclusions}

Facultative enteropathogens are exposed to antibiotics under aerobic and anaerobic conditions during their life history in both the human gut and in the environment. We used the facultative enteropathogen $V$. cholerae as a model to test for differences in AMR phenotypes under aerobic and anaerobic conditions. The odds of classifying isolates as resistant under anaerobic compared to aerobic conditions increased over 10 times for two of the three antibiotics tested. While several known resistance genes were associated with AMR under both conditions, many genes were only associated with AMR under one condition. In general, heritability tended to be higher and more genes associated with resistance under anaerobic conditions, suggesting that key genetic determinants of resistance may be missed when experiments are only performed aerobically. Taken together, these findings challenge the paradigm of testing facultative enteropathogens for AMR under aerobic conditions alone. The experimental approach herein may also establish a new, less biased framework to track and investigate mechanisms of AMR. 


\section{Acknowledgements}

428 We thank the patients for participating in this study and the icddr,b clinical and laboratory teams

429 that collected the samples. We are grateful to Randy Autrey and Krista Berquist for their

430 administrative expertise, as well as Glenn Morris at the Emerging Pathogens Institute and

431 Desmond Schatz in the Department of Pediatrics for their ongoing support at the University of

432 Florida. Stephen Calderwood, Jason Harris, and Regina LaRocque were the principal

433 investigators $(\mathrm{PI})$ of the parent study/IRB protocol (Massachusetts General Hospital, Harvard

434 University School of Medicine, USA) under which the samples were collected by EJN when he

435 was a NIH Fogarty Fellow. Andrew Camilli provided additional reagents and insights for this

436 manuscript; FQ was the principal investigator in Bangladesh and PI of the ERC/RRC approvals

437 at the icddr,b. This generous research infrastructure and support was invaluable to the success

438 of this study.

\section{Data availability}

440 Data analyzed in the manuscript have been made available in the online supplementary

441 material

\section{$442 \quad$ Financial Support}

443 This work was supported by the National Institutes of Health grants to EJN [DP5OD019893] and

444 KBB [S10 OD021758-01A1] and internal support from the Emerging Pathogens Institute, the

Departments of Pediatrics and the Department of Environmental and Global Health at the

446 University of Florida. BJS and MMS were supported by a Genome Canada and Genome

447 Quebec Bioinformatics and Computational Biology grant.

\section{Disclaimer}

449 The funders had no role in study design, data collection and analysis, decision to publish, or 450 preparation of the manuscript. 
bioRxiv preprint doi: https://doi.org/10.1101/2021.06.26.450051; this version posted June 27, 2021. The copyright holder for this preprint (which was not certified by peer review) is the author/funder, who has granted bioRxiv a license to display the preprint in perpetuity. It is made available under aCC-BY-NC-ND 4.0 International license.

\section{Potential conflicts of interest.}

452 All authors: No reported conflicts. 


\section{FIGURES}

\section{FIGURE 1}

a

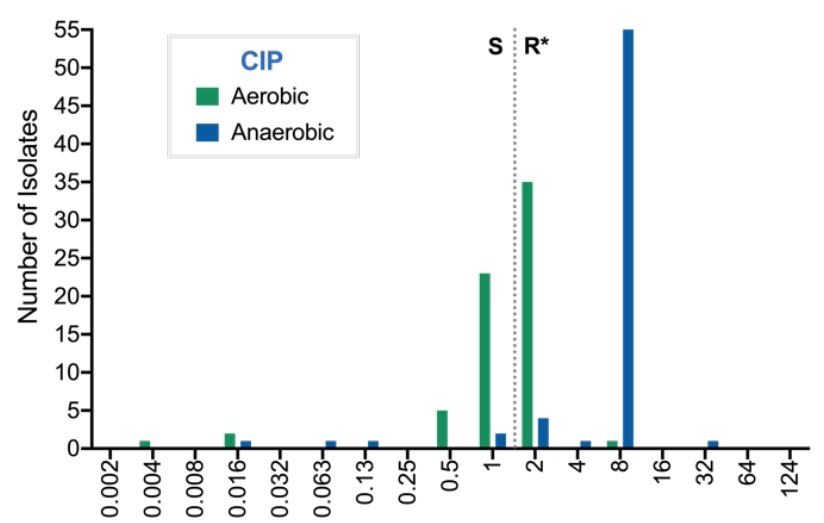

b

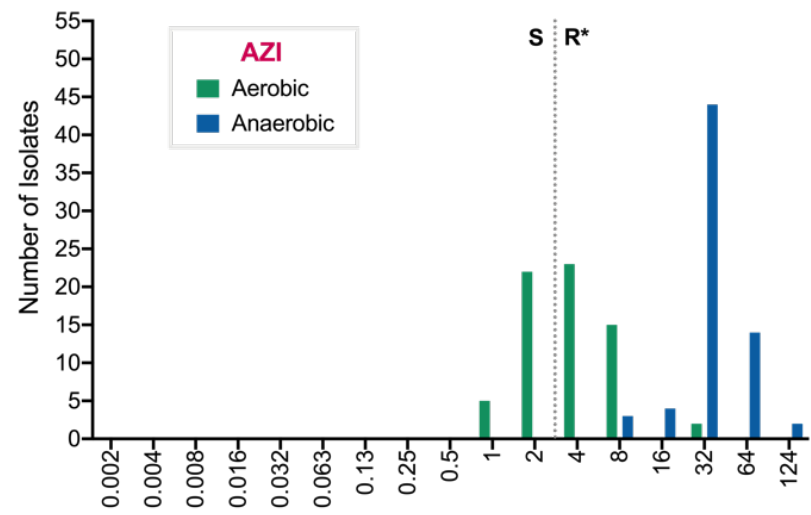

C

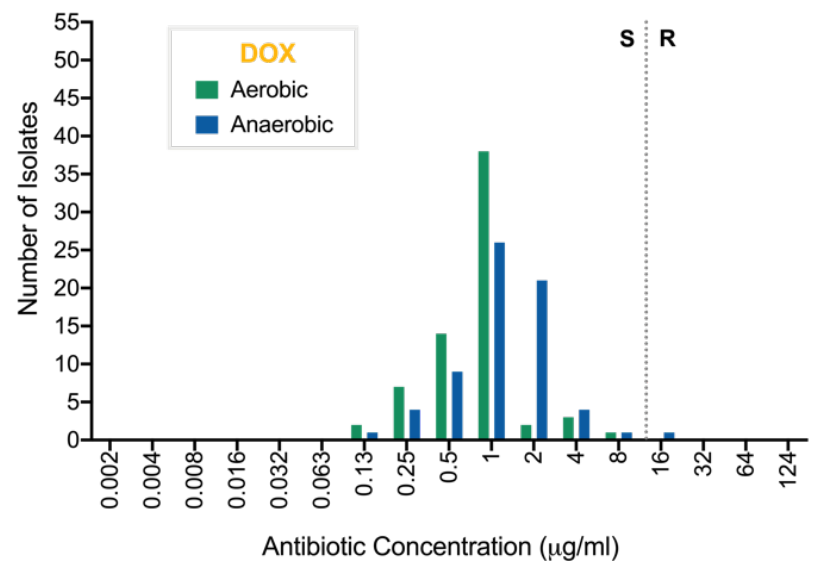

Antibiotic Concentration $(\mu \mathrm{g} / \mathrm{ml})$

Fig. 1. Distribution of antibiotic resistance among clinical isolates under aerobic and anaerobic conditions. Ciprofloxacin (CIP; a), Azithromycin (AZI; b), and Doxycycline (DOX; c). Resistance was determined by MIC under aerobic (green) and anaerobic conditions (blue). Data are from 67 human-shed $V$. cholerae isolates. Dotted line is the breakpoint for resistance per CLSI standards (CIP = $2 \mu \mathrm{g} / \mathrm{ml} ; \mathrm{AZI}=$ $4 \mu \mathrm{g} / \mathrm{ml}$; DOX $=16 \mu \mathrm{g} / \mathrm{ml}$ ). "*” represents a significant difference in the frequency of isolates identified as resistant to ciprofloxacin and azithromycin by McNemar's test (both $p<0.001)$. $S=$ sensitive. $R=$ Resistant. 


\section{FIGURE 2}

465

a.

\section{AMR Phenotype}

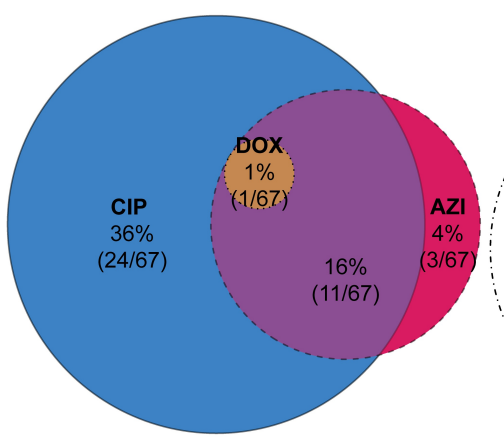

Aerobic

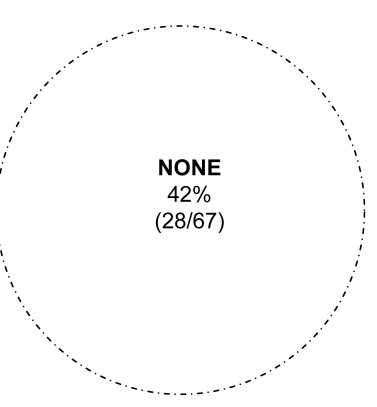

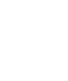

b.

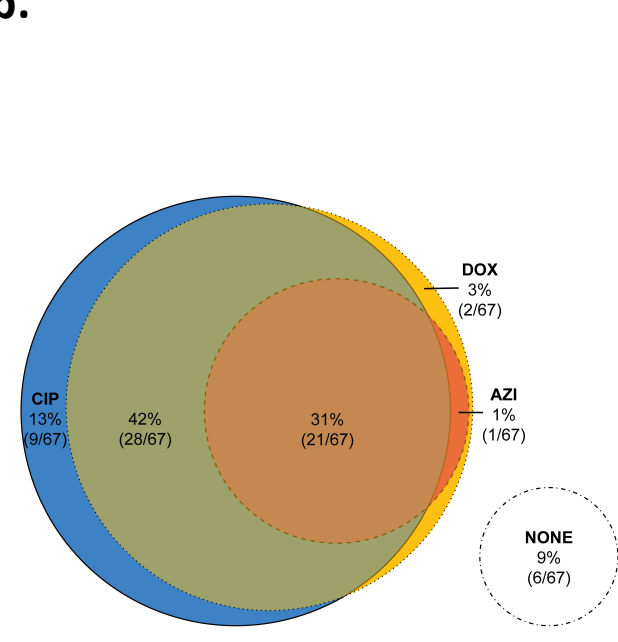

Fig. 2. AMR phenotypes and known AMR genetic elements in human-shed $\boldsymbol{V}$. cholerae isolates. a, Proportional Venn diagram (Euler) of AMR phenotypes to azithromycin (AZI), doxycycline (DOX) and/or ciprofloxacin (CIP) under aerobic (left) and anaerobic conditions (right). b. Distribution of specific known AMR genetic elements by proportional Venn diagram (Euler; left) and bar chart (right). AMR genetic elements to other antibiotics are not shown.

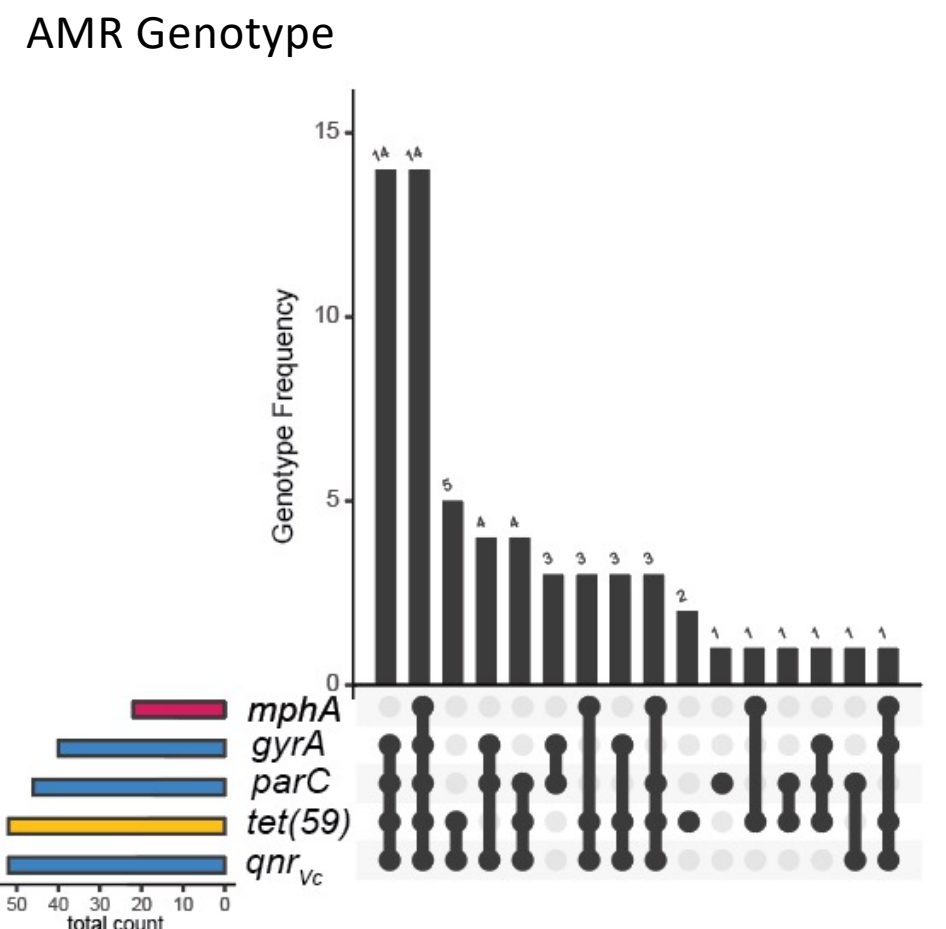


bioRxiv preprint doi: https://doi.org/10.1101/2021.06.26.450051; this version posted June 27, 2021. The copyright holder for this preprint (which was not certified by peer review) is the author/funder, who has granted bioRxiv a license to display the preprint in perpetuity. It is made available under aCC-BY-NC-ND 4.0 International license.

a

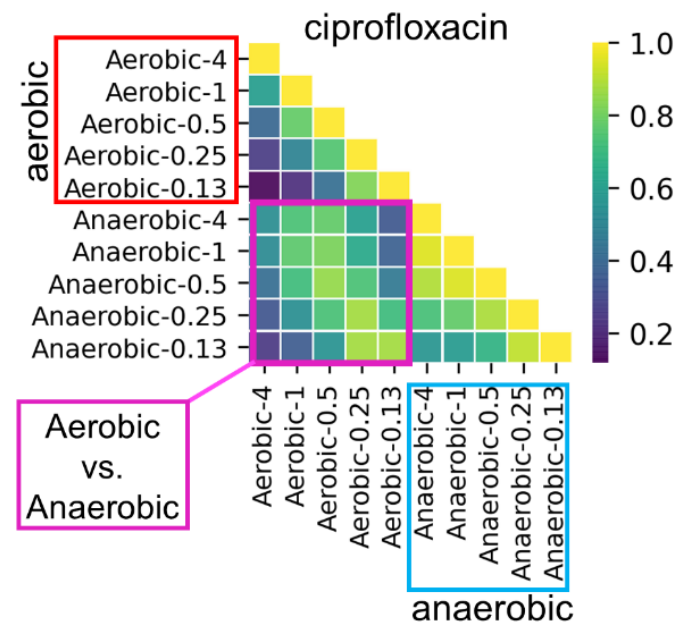

b

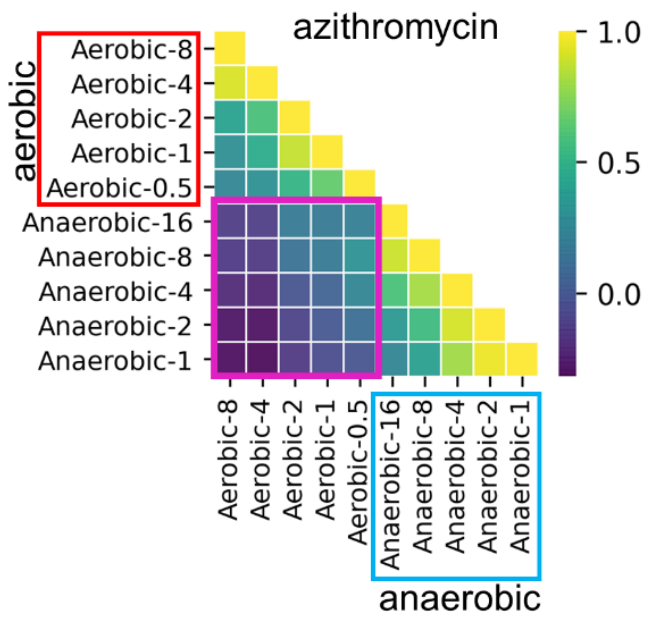

C

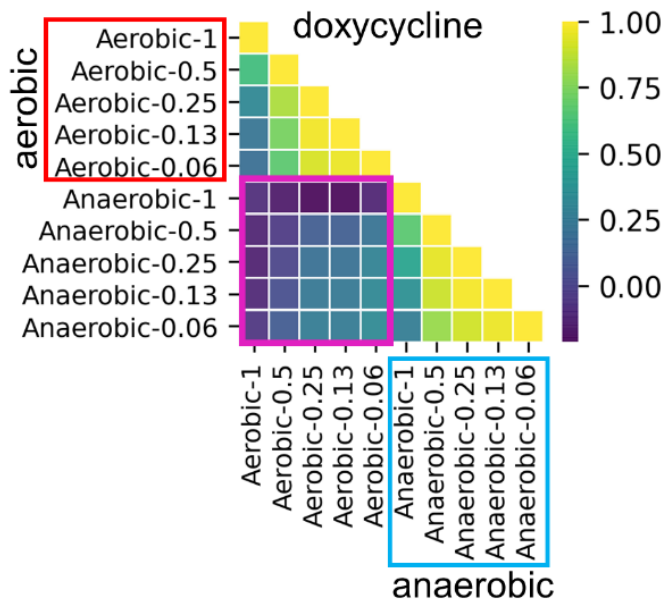

Fig. 3. Correlations among $V$. cholerae growth phenotypes at different concentration of antibiotics and respiratory conditions. Correlations of $V$. cholerae growth phenotypes (AUC) to ciprofloxacin (CIP; a), azithromycin (AZl; b), and doxycycline (DOX; c) at different antibiotic concentrations under aerobic and anaerobic conditions (e.g. "Anaerobic-0.06"). Heatmaps show correlation coefficients (scale bar is to right). 
a cds-WP 000041081.1 cds-WP 001883086.1 cds-WP 014164112.1 cds-WP 014378730.1 cds-WP_072615218.1 cds-WP_079857360.1

\section{Ciprofloxacin}

Aerobic vs. Anaerobic

Aerobic

Anaerobic

$$
r t \times B
$$

cds-CSW01_RS08165

cds-WP_000349829.1

cds-WP_000762048.1

cds-WP_001191814.1

cds-WP 001247622.1

cds-WP_001252112.1

cds-WP_001890112.1

cds-WP_001917086.1

cds-WP_001999499.1

b

\section{Ciprofloxacin Aerobic}

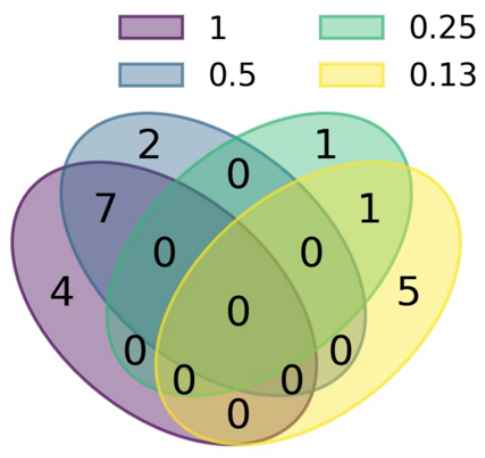

barA radC cds-CSW01_RS05905 cds-WP_000348847.1 cds-WP_001129562.1 cds-WP_001230753.1 cds-WP_001279526.1 d Doxycycline Anaerobic
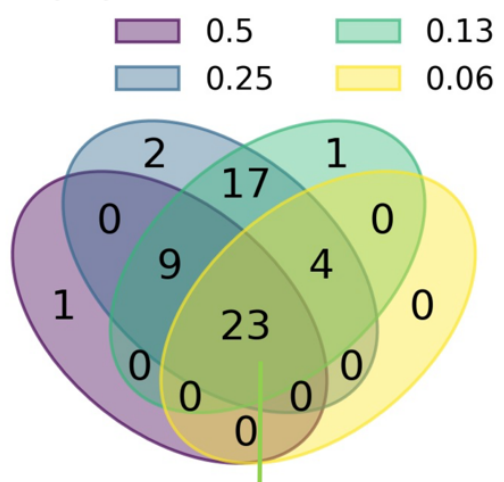

tet(59) recD suhB znuC

cobB fadJ glmM mutL nudF putA radC rarD cds-WP_000041081.1 cds-WP_000066839.1 cds-WP_000072017.1 cds-WP_000572493.1 cds-WP_000960654.1 cds-WP_001116764.1 cds-WP_001230753.1 cds-WP_001253226.1 cds-WP_001279526.1 cds-WP_001881762.1 cds-WP_001883330.1

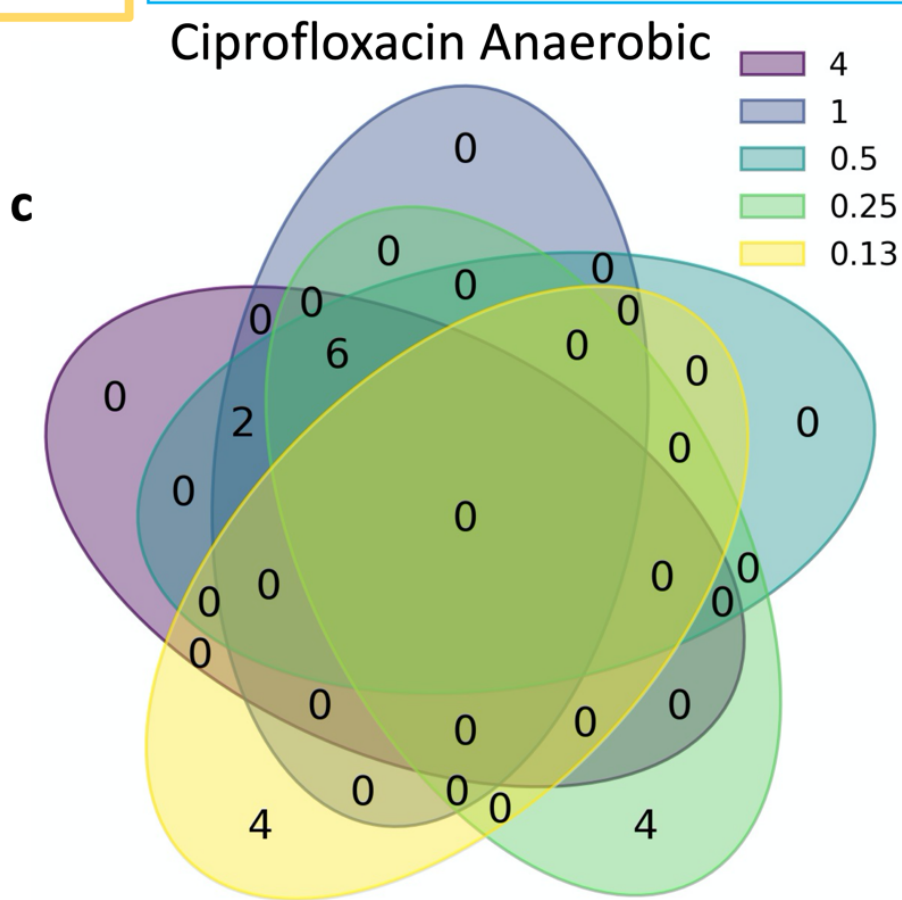

Fig. 4. Distribution of AMR genes associated with AMR growth phenotypes at different concentrations of antibiotics under aerobic and anaerobic conditions. Venn diagrams show the overlap between genes associated with (a) ciprofloxacin (CIP) resistance under aerobic vs. anaerobic conditions, (b) ciprofloxacin at different concentrations $(\mu \mathrm{g} / \mathrm{ml})$ under aerobic conditions, (c) ciprofloxacin at different concentrations $(\mu \mathrm{g} / \mathrm{ml})$ under anaerobic conditions, and $(\mathrm{d})$ doxycycline at different concentrations $(\mu \mathrm{g} / \mathrm{ml})$ under anaerobic conditions. 


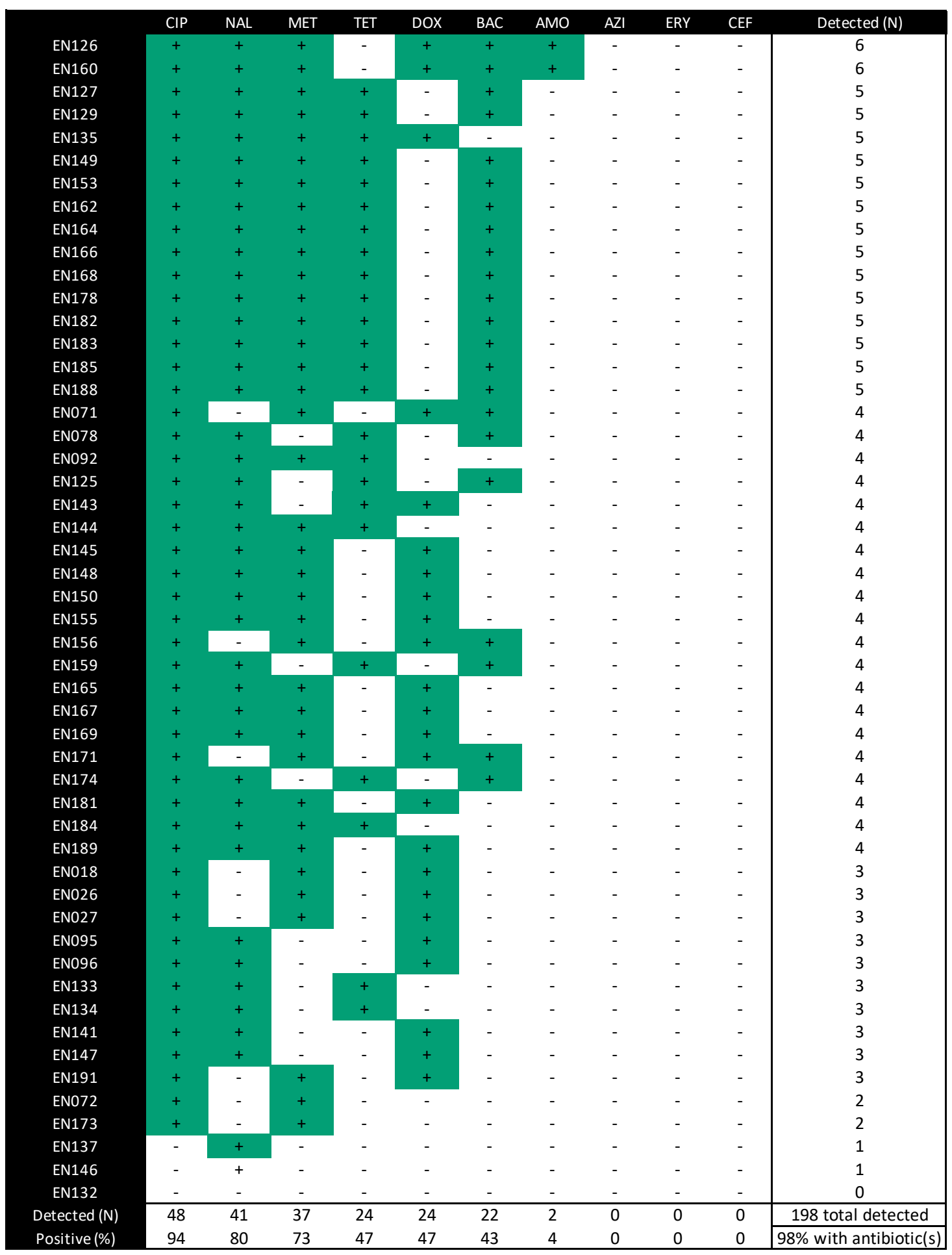


497 Table 1. Identification of genetic elements by GWAS that associate with AMR.

\begin{tabular}{|c|c|c|c|c|c|c|}
\hline \multirow{2}{*}{$\begin{array}{l}\text { Condition } \\
\text { Ciprofloxacin }^{\mathrm{a}}\end{array}$} & \multirow[t]{2}{*}{ Outcome $^{\mathrm{b}}$} & \multicolumn{5}{|c|}{ Antibiotic Concentration $(\mu \mathrm{g} / \mathrm{ml})$} \\
\hline & & CIP4 & CIP1 & CIP0.5 & CIP0.25 & CIP0.13 \\
\hline \multirow[t]{2}{*}{ Aerobic } & Heritability $\left(\mathrm{h}^{2}\right)$ & 0.99 & 0.73 & 0.60 & 0.74 & 0.92 \\
\hline & Associated genes & 0 & 11 & 9 & 2 & 6 \\
\hline \multirow[t]{2}{*}{ Anaerobic } & Heritability $\left(h^{2}\right)$ & 0.81 & 0.73 & 0.72 & 0.72 & 0.87 \\
\hline & Associated genes & 8 & 8 & 8 & 10 & 4 \\
\hline \multicolumn{2}{|l|}{ Azithromycin ${ }^{a}$} & AZI16 & AZI8 & AZI4 & AZI2 & AZI1 \\
\hline \multirow[t]{2}{*}{ Aerobic } & Heritability $\left(h^{2}\right)$ & - & 0.00 & 0.02 & 0.00 & 0.11 \\
\hline & Associated genes & - & - & - & - & - \\
\hline \multirow[t]{2}{*}{ Anaerobic } & Heritability $\left(h^{2}\right)$ & 0.30 & 0.77 & 0.66 & 0.38 & 0.00 \\
\hline & Associated genes & 2 & 1 & 0 & 0 & - \\
\hline \multicolumn{2}{|l|}{ Doxycycline $^{a}$} & DOX1 & DOX0.5 & DOX0.25 & DOX0.13 & DOX0.06 \\
\hline \multirow[t]{2}{*}{ Aerobic } & Heritability $\left(\mathrm{h}^{2}\right)$ & 0.00 & 0.27 & 0.23 & 0.30 & 0.50 \\
\hline & Associated genes & - & 0 & 0 & 0 & 0 \\
\hline \multirow[t]{2}{*}{ Anaerobic } & Heritability $\left(h^{2}\right)$ & 0.10 & 0.61 & 0.72 & 0.72 & 0.77 \\
\hline & Associated genes & 0 & 23 & 55 & 54 & 17 \\
\hline
\end{tabular}

${ }^{\mathrm{a}}$ Ciprofloxacin = CIP; Azithromycin = AZI; Doxycycline = DOX

${ }^{b}$ Heritability is the proportion of phenotypic variation that is explained by genetic variation. Associated

500 genes are all significant GWAS hits after correction for multiple hypothesis testing $(P<0.05$ after

501 Bonferroni correction).

502 


\section{SUPPLEMENTATRY MATERIAL}

506 Table of Contents

507 Supplementary Table 1. Reference strains and clinical isolates

508 Supplementary Table 2. Baseline growth parameters of $\mathrm{V}$. cholerae clinical isolates

509 under aerobic and anaerobic conditions

510 Supplementary Table 3. Minimal inhibitory concentrations (MICs) for ciprofloxacin,

511 azithromycin, and doxycycline among $V$. cholerae clinical isolates

512 Supplementary Table 4. Comparison of rates of resistance detected under aerobic

513 versus anaerobic conditions among $V$. cholerae clinical isolates

514 Supplementary Table 5. Effect of catalase on growth parameters for V. cholerae E7946

515 and EN160 under aerobic conditions

516 Supplementary Table 6. Comparison of antibiotic resistance phenotypes and known

517 resistance genotypes among $V$. cholerae clinical isolates

518 Supplementary Table 7. Test of association between antibiotic detection by mass

519 spectrometry and AMR genotypes and phenotypes among V. cholerae clinical isolates

Date File S1. GWAS Hits. Ciprofloxacin resistance phenotype. Aerobic. 
530 Supplementary Table 1. Reference strains and clinical isolates

\begin{tabular}{|c|c|c|c|c|c|c|c|c|}
\hline & \multirow[b]{2}{*}{ Strain ${ }^{a}$} & \multicolumn{3}{|c|}{ Aerobic $^{b}$} & \multicolumn{3}{|c|}{ Anaerobic $^{b}$} & \multirow[t]{2}{*}{ Source ${ }^{c}$} \\
\hline & & CIPR & $A Z I^{R}$ & $\mathrm{DOC}^{\mathrm{R}}$ & $\mathrm{CIP}^{\mathrm{R}}$ & $A Z I^{R}$ & DOX R & \\
\hline Reference & E7946 & + & - & - & + & - & - & (1) \\
\hline \multicolumn{9}{|c|}{ Clinical Isolates } \\
\hline EN018 & L_EN1286 & - & - & - & - & + & - & (2) \\
\hline EN026 & L_EN1291 & - & - & - & - & + & - & $(2)$ \\
\hline EN027 & L_EN1292 & - & - & - & - & + & - & (2) \\
\hline EN071 & L_EN1300 & + & - & - & + & + & - & (2) \\
\hline EN072 & L_EN1301 & - & - & - & + & + & - & (2) \\
\hline EN078 & L_EN1303 & + & - & - & + & + & - & (2) \\
\hline EN079 & L_EN1304 & - & + & - & + & + & - & (2) \\
\hline EN080 & L_EN1305 & + & - & - & + & + & - & $(2)$ \\
\hline EN086 & L_EN1307 & + & + & - & + & + & - & (2) \\
\hline EN088 & L_EN1308 & + & - & - & + & + & - & (2) \\
\hline EN092 & L_EN1310 & + & - & - & + & + & - & $(2)$ \\
\hline EN095 & L_EN1312 & + & + & - & + & + & - & (2) \\
\hline EN096 & L_EN1313 & + & + & - & + & + & - & (2) \\
\hline EN100 & L_EN1314 & + & + & - & + & + & - & (2) \\
\hline EN103 & L_En1315 & - & - & - & + & + & - & (2) \\
\hline EN109 & L_EN1319 & - & - & - & + & + & - & (2) \\
\hline EN116 & L_EN1325 & - & - & - & + & + & - & (2) \\
\hline EN117 & L_EN1326 & - & - & - & - & + & - & (2) \\
\hline EN118 & L_EN1327 & - & + & - & + & + & - & (2) \\
\hline EN119 & L_EN1328 & + & - & - & + & + & - & (2) \\
\hline EN120 & L_EN1329 & - & - & - & + & + & - & (2) \\
\hline EN123 & L_EN1330 & - & - & - & + & + & - & (2) \\
\hline EN124 & L_EN1331 & + & - & - & + & + & - & (2) \\
\hline EN125 & L_EN1332 & + & + & - & + & + & - & (2) \\
\hline EN126 & L_EN1333 & + & - & - & + & + & - & $(2)$ \\
\hline EN127 & L_EN1334 & + & - & - & + & + & - & (2) \\
\hline EN129 & L_EN1335 & - & - & - & + & + & - & (2) \\
\hline EN130 & L_EN1336 & + & - & - & + & + & - & (2) \\
\hline EN131 & L_EN1337 & + & - & - & + & + & - & (2) \\
\hline EN132 & L_EN1338 & + & - & - & + & + & - & (2) \\
\hline EN133 & L_EN1339 & + & - & - & + & + & - & $(2)$ \\
\hline EN134 & L_EN1340 & - & + & - & + & + & - & (2) \\
\hline
\end{tabular}




\begin{tabular}{|c|c|c|c|c|c|c|c|c|}
\hline EN135 & L_EN1341 & - & - & - & + & + & - & $(2)$ \\
\hline EN137 & L_EN1343 & + & + & - & + & + & - & (2) \\
\hline EN141 & L_EN1344 & + & - & - & + & + & - & (2) \\
\hline EN143 & L_EN1346 & - & - & - & + & + & - & (2) \\
\hline EN144 & L_EN1347 & + & - & - & + & + & - & (2) \\
\hline EN145 & L_EN1348 & + & + & - & + & + & + & (2) \\
\hline EN146 & L_EN1349 & + & - & - & + & + & - & (2) \\
\hline EN147 & L_EN1350 & - & - & - & + & + & - & (2) \\
\hline EN148 & L_EN1351 & - & - & - & + & + & - & (2) \\
\hline EN149 & L_EN1352 & + & - & - & + & + & - & (2) \\
\hline EN150 & L_EN1353 & - & - & - & + & + & - & (2) \\
\hline EN153 & L_EN1355 & - & - & - & + & + & - & (2) \\
\hline EN155 & L_EN1357 & + & - & - & + & + & - & (2) \\
\hline EN156 & L_EN1358 & - & - & - & + & + & - & (2) \\
\hline EN159 & L_EN1360 & + & + & - & + & + & - & (2) \\
\hline EN160 & L_EN1361 & + & - & - & + & + & - & (2) \\
\hline EN162 & L_EN1363 & + & + & - & + & + & - & (2) \\
\hline EN164 & L_EN1365 & - & - & - & + & + & - & (2) \\
\hline EN165 & L_EN1366 & + & - & - & + & + & - & (2) \\
\hline EN166 & L_EN1367 & + & - & - & + & + & - & (2) \\
\hline EN167 & L_EN1368 & + & - & - & + & + & - & (2) \\
\hline EN168 & L_EN1369 & + & + & - & + & + & - & (2) \\
\hline EN169 & L_EN1370 & - & - & - & + & + & - & (2) \\
\hline EN171 & L_EN1371 & + & + & - & + & + & - & $(2)$ \\
\hline EN173 & L_EN1372 & - & - & - & + & + & - & $(2)$ \\
\hline EN174 & L_EN1374 & - & - & - & + & + & - & (2) \\
\hline EN178 & L_EN1377 & + & - & - & + & + & - & $(2)$ \\
\hline EN181 & L_EN1379 & - & - & - & - & + & - & (2) \\
\hline EN182 & L_En1380 & - & - & - & + & + & - & $(2)$ \\
\hline EN183 & L_EN1381 & - & - & - & + & + & - & $(2)$ \\
\hline EN184 & L_EN1382 & + & - & - & + & + & - & (2) \\
\hline EN185 & L_EN1383 & - & - & - & + & + & - & (2) \\
\hline EN188 & L_EN1385 & - & - & - & + & + & - & (2) \\
\hline EN189 & L_EN1386 & + & + & - & + & + & - & (2) \\
\hline EN191 & L_EN1388 & - & - & - & + & + & - & $(2)$ \\
\hline
\end{tabular}

532 a Prefix of "L_" was used to distinguish the strain number in the library from the clinical isolate number, which is maintained to be consistent with prior publications.

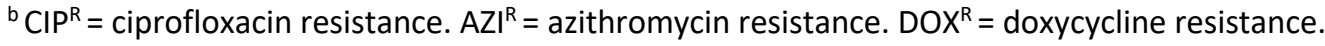


bioRxiv preprint doi: https://doi.org/10.1101/2021.06.26.450051; this version posted June 27, 2021. The copyright holder for this preprint (which was not certified by peer review) is the author/funder, who has granted bioRxiv a license to display the preprint in perpetuity. It is made available under aCC-BY-NC-ND 4.0 International license.

538 Supplementary Table 2. Baseline growth parameters of $V$. cholerae clinical isolates

539 under aerobic and anaerobic conditions

540

\begin{tabular}{lccc}
\hline Growth parameter $^{\mathrm{a}}$ & $\begin{array}{c}\text { Aerobic } \\
\text { median }\end{array}$ & $\begin{array}{c}\text { Anaerobic } \\
\text { median }\end{array}$ & $\mathrm{P}^{\mathrm{b}}$ \\
\hline $\mathrm{K}$ & 1.08 & 0.261 & $<\mathbf{0 . 0 0 1}$ \\
$\mathrm{AUC}$ & 5.15 & 1.58 & $<\mathbf{0 . 0 0 1}$ \\
Velocity & 0.011 & 0.006 & $<\mathbf{0 . 0 0 1}$
\end{tabular}

$541{ }^{a}$ AUC = area under the curve. $\mathrm{K}=$ carrying capacity. Media was LB alone without antibiotics. Velocity = 542 growth rate in percent increase per minute at half the carrying capacity.

$543{ }^{b}$ Wilcoxon signed-rank test for growth. Bold $=$ statistically significant $(P<0.05)$.

544 
545 Supplementary Table 3. Minimal inhibitory concentrations (MICs) for 546 ciprofloxacin, azithromycin, and doxycycline among $V$. cholerae clinical

547 isolates

548

\begin{tabular}{c|cccccc}
\hline & \multicolumn{2}{c}{ Ciprofloxacin $^{\mathrm{b}}$} & \multicolumn{2}{c}{ Azithromycin $^{\mathrm{b}}$} & \multicolumn{2}{c}{ Doxycycline $^{\mathrm{b}}$} \\
$\mu \mathrm{g} / \mathrm{ml}^{\mathrm{a}}$ & Aerobic & Anaerobic & Aerobic & Anaerobic & Aerobic & Anaerobic \\
\hline 0.002 & 0 & 0 & 0 & 0 & 0 & 0 \\
0.004 & 1 & 0 & 0 & 0 & 0 & 0 \\
0.008 & 0 & 0 & 0 & 0 & 0 & 0 \\
0.016 & 2 & 1 & 0 & 0 & 0 & 0 \\
0.032 & 0 & 0 & 0 & 0 & 0 & 0 \\
0.063 & 0 & 1 & 0 & 0 & 0 & 0 \\
0.13 & 0 & 1 & 0 & 0 & 2 & 1 \\
0.25 & 0 & 0 & 0 & 0 & 7 & 4 \\
0.5 & 5 & 0 & 0 & 0 & 14 & 9 \\
1 & 23 & 2 & 5 & 0 & 38 & $\mathbf{2 6}$ \\
2 & 35 & 4 & 22 & 0 & 2 & 21 \\
4 & 0 & 1 & 23 & 0 & 3 & 4 \\
8 & 1 & 56 & 15 & 3 & 1 & 1 \\
16 & 0 & 0 & 0 & 4 & 0 & 1 \\
32 & 0 & 1 & 2 & 44 & 0 & 0 \\
64 & 0 & 0 & 0 & 14 & 0 & 0 \\
124 & 0 & 0 & 0 & 2 & 0 & 0 \\
\hline
\end{tabular}

$549 \quad{ }^{a}$ Concentration of antibiotic.

$550{ }^{b}$ Distribution of MICs for clinical isolates grown under aerobic and anaerobic conditions. Bold text signifies the concentration at which the MIC mode was determined among the clinical isolates. 
bioRxiv preprint doi: https://doi.org/10.1101/2021.06.26.450051; this version posted June 27, 2021. The copyright holder for this preprint (which was not certified by peer review) is the author/funder, who has granted bioRxiv a license to display the preprint in perpetuity. It is made available under aCC-BY-NC-ND 4.0 International license.

553 Supplementary Table 4. Comparison of rates of resistance detected under aerobic

554 versus anaerobic conditions among $V$. cholerae clinical isolates

555

\begin{tabular}{lcccccccc}
\hline & $\mathrm{N}$ & $\mathrm{R}^{\mathrm{Ae}} / \mathrm{R}^{\mathrm{An}}$ & $\mathrm{R}^{\mathrm{Ae}} / \mathrm{S}^{\mathrm{An}}$ & $\mathrm{S}^{\mathrm{Ae}} / \mathrm{R}^{\mathrm{An}}$ & $\mathrm{S}^{\mathrm{Ae}} / \mathrm{S}^{\mathrm{An}}$ & $\mathrm{OR}^{\mathrm{b}}$ & $95 \% \mathrm{Cl}^{\mathrm{b}}$ & $\mathrm{P}^{\mathrm{b}}$ \\
\hline Ciprofloxacin $^{\mathrm{a}}$ & 67 & 36 & 0 & 26 & 5 & 27 & $(4.45-1105)$ & $<\mathbf{0 . 0 0 1}$ \\
Azithromycin $^{\mathrm{a}}$ & 67 & 15 & 0 & 52 & 0 & 53 & $(9.10-2132)$ & $<\mathbf{0 . 0 0 1}$ \\
Doxycycline $^{\mathrm{a}}$ & 67 & 0 & 1 & 1 & 65 & 1 & $(0.01-78.5)$ & 1 \\
\hline
\end{tabular}

556 a Distribution of paired resistant ('R') and sensitive ('S') phenotypes for isolates under aerobic ('Ae') and 557 anaerobic ('An') conditions.

$558{ }^{b}$ McNemar's Exact Test. Bold $=$ statistically significant $(P<0.05)$ 
560 Supplementary Table 5. Effect of catalase on growth parameters for $V$. cholerae E7946 and EN160 under aerobic conditions

562

\begin{tabular}{llccccc}
\hline Experiment & Strain $^{\mathrm{a}}$ & Antibiotic $^{\mathrm{b}}$ & Catalase $^{\mathrm{c}}$ & AUC mean $^{\mathrm{d}}$ & AUC IQR $^{\mathrm{d}}$ & $\mathrm{P}^{\mathrm{e}}$ \\
\hline 1. & E7946 & CIP & YES & 41.84 & 1.76 & 0.136 \\
& & CIP & NO & 44.2 & 0.865 & \\
\hline 2. & E7946 & AZI & YES & 196 & 3.37 & 0.533 \\
& & AZI & NO & 197.5 & 0.294 & \\
\hline 3. & E7946 & DOX & YES & 308.5 & 6.32 & 0.959 \\
& & DOX & NO & 308.9 & 4.11 & \\
\hline 4. & E7946 & NO & YES & 317.3 & 4.65 & 0.818 \\
& & NO & NO & 318 & 5.42 & \\
\hline 5. & EN160 & CIP & YES & 138.4 & 22.1 & 0.551 \\
& & CIP & NO & 126.1 & 25.2 & \\
\hline 7. & EN160 & AZI & YES & 265.8 & 7.12 & 0.571 \\
& & AZI & NO & 269.9 & 6.75 & \\
\hline 8 & EN160 & DOX & YES & 280.1 & 19.3 & 0.895 \\
& & DOX & NO & 275.8 & 21.6 & \\
\hline
\end{tabular}

${ }^{a} \mathrm{E} 7946\left(\mathrm{Cip}^{\mathrm{S}}, \mathrm{Azi}^{\mathrm{S}}, \mathrm{Dox}{ }^{\mathrm{S}}\right)$ is the reference strain and $\mathrm{EN} 160\left(\mathrm{Cip}^{\mathrm{R}}, \mathrm{Azi}^{\mathrm{R}}, \mathrm{Dox}{ }^{\mathrm{S}}\right)$ is a clinical isolate.

564 Biological replicates in experiments 1-3 and 5-7 were 3, each with 4 technical replicates. Biological replicates for experiments 4 and 8 were 9 , each with 4 technical replicates.

566

${ }^{\mathrm{b}} \mathrm{CIP}=$ ciprofloxacin. $\mathrm{AZI}=$ azithromycin. $\mathrm{DOX}=$ doxycycline. Assays were run at $\mathrm{CIP}=0.5, \mathrm{AZI}=2$, and

567

$\mathrm{DOX}=0.25 \mu \mathrm{g} / \mathrm{ml}$ for EN160; E7946 was run at CIP $=0.002, \mathrm{AZI}=1$, and $\mathrm{DOX}=0.013$

$568 \mu \mathrm{g} / \mathrm{ml}$.

$569{ }^{\mathrm{c}} \mathrm{CIP}$ and AZI were tested with 3 biological replicates; DOX with 2 biological replications; LB controls with 5709 biological replicates.

$571 \quad{ }^{\mathrm{d}} \mathrm{AUC}=$ area under the curve. IQR $=$ interquartile range.

572 e Student's t-test. Bold = statistically significant $(\mathrm{P}<0.05)$ 
573 Supplementary Table 6. Comparison of antibiotic resistance phenotypes and known

574 resistance genotypes among $V$. cholerae clinical isolates

\begin{tabular}{|c|c|c|c|c|c|c|c|c|}
\hline \multicolumn{9}{|c|}{ Aerobic conditions ${ }^{a}$} \\
\hline Antibiotic tested & Gene & $\mathrm{R} / \mathrm{P}$ & $\mathrm{R} / \mathrm{NP}$ & $\mathrm{S} / \mathrm{P}$ & S/NP & $\mathrm{OR}^{\mathrm{b}}$ & $95 \% \mathrm{Cl}^{\mathrm{b}}$ & $\mathrm{P}^{\mathrm{b}}$ \\
\hline \multirow[t]{3}{*}{ Ciprofloxacin } & qnrVc & 36 & 0 & 16 & 15 & 31 & $(4.22-695)$ & $<0.001$ \\
\hline & gyrA & 28 & 8 & 12 & 19 & 5.4 & $(1.86-17.9)$ & 0.002 \\
\hline & parC & 31 & 5 & 16 & 15 & 5.6 & $(1.65-18.9)$ & 0.003 \\
\hline Azithromycin & $m p h A$ & 15 & 0 & 7 & 45 & 83 & $(11.2-1938)$ & $<0.001$ \\
\hline Doxycycline & tet(59) & 1 & 0 & 51 & 15 & 0.62 & $(0.046-18.9)$ & 0.566 \\
\hline \multicolumn{9}{|c|}{ Anaerobic conditions ${ }^{a}$} \\
\hline Antibiotic tested & Gene & $\mathrm{R} / \mathrm{P}$ & $\mathrm{R} / \mathrm{NP}$ & $\mathrm{S} / \mathrm{P}$ & S/NP & $\mathrm{OR}^{\mathrm{b}}$ & $95 \% \mathrm{Cb}^{\mathrm{c}}$ & $\mathrm{P}^{\mathrm{b}}$ \\
\hline \multirow[t]{3}{*}{ Ciprofloxacin } & qnrVc & 52 & 10 & 0 & 5 & 27 & $(3.53-666)$ & $<0.001$ \\
\hline & gyrA & 40 & 22 & 0 & 5 & 10 & $(1.39-248)$ & 0.016 \\
\hline & parC & 47 & 15 & 0 & 5 & 17 & $(2.28-416)$ & 0.003 \\
\hline Azithromycin & $m p h A$ & 22 & 45 & 0 & 0 & 0.51 & $(0.0127-20.1)$ & 1 \\
\hline Doxycycline & tet(59) & 1 & 0 & 51 & 15 & 0.62 & $(0.046-18.9)$ & 0.566 \\
\hline
\end{tabular}

${ }^{\mathrm{b}}$ Fisher's Exact Test. Bold $=$ statistically significant $(\mathrm{P}<0.05)$ 
581 Supplementary Table 7. Test of association between antibiotic detection by 582 mass spectrometry and AMR genotypes and phenotypes among $V$. cholerae

583 clinical isolates

\begin{tabular}{lccccc}
\hline \multicolumn{7}{l}{ Antibiotic detection (D) and AMR genotype present (P) $)^{a}$} \\
& D/P & D/NP & ND/P & ND/NP & $P^{b}$ \\
\hline CIP & 41 & 7 & 3 & 0 & 1 \\
CIP + NAL & 35 & 4 & 9 & 3 & 0.334 \\
DOX & 16 & 8 & 20 & 7 & 0.759 \\
DOX + TET & 2 & 0 & 34 & 15 & 1 \\
\hline
\end{tabular}

Antibiotic detection (D) and resistance phenotype (R) under aerobic conditions ${ }^{a}$

\begin{tabular}{lccccc} 
& D/R & D/S & ND/R & ND/S & $P^{b}$ \\
\hline CIP & 24 & 24 & 3 & 0 & 0.238 \\
CIP + NAL & 22 & 17 & 5 & 7 & 0.511 \\
DOX & 1 & 23 & 0 & 27 & 0.471 \\
DOX + TET & 0 & 2 & 1 & 48 & 1 \\
\hline
\end{tabular}

Antibiotic detection (D) and resistance phenotype (R) under anaerobic conditions ${ }^{a}$

\begin{tabular}{lccccc} 
& D/R & D/S & ND/R & ND/S & $P^{\mathrm{b}}$ \\
\hline CIP & 44 & 4 & 3 & 0 & 1 \\
CIP + NAL & 38 & 1 & 9 & 3 & $\mathbf{0 . 0 3 6}$ \\
DOX & 1 & 23 & 0 & 27 & 0.217 \\
DOX + TET & 0 & 2 & 1 & 48 & 1 \\
\hline
\end{tabular}

$584 \quad \mathrm{D}=$ detected, $\mathrm{ND}=$ not detected, $\mathrm{R}=$ resistant by MIC, $\mathrm{S}=$ sensitive by MIC, $\mathrm{P}=$ Present, NP

$585=$ Not present.

$586 \quad{ }^{b}$ Fisher's Exact Test. Bold $=$ statistically significant $(P<0.05)$ 
588

589

5901 Chun, C., Zheng, L. \& Colgan, S. P. Tissue metabolism and host-microbial

591

592

593

594

595

596

597

598

599

600

601

602

603

604

605

606

607

608

609

610

\section{REFERENCES}

interactions in the intestinal mucosa. Free Radic Biol Med 105, 86-92,

doi:10.1016/j.freeradbiomed.2016.09.027 (2017).

2 Zheng, L., Kelly, C. J. \& Colgan, S. P. Physiologic hypoxia and oxygen

homeostasis in the healthy intestine. A Review in the Theme: Cellular Responses

to Hypoxia. Am J Physiol Cell Physiol 309, C350-360,

doi:10.1152/ajpcell.00191.2015 (2015).

3 Performance Standards for Antimicrobial Susceptibility Testing. 27th edn, (Clinical and Laboratory Standards Institue (CLSI), 2017).

4 Bueno, E., Sit, B., Waldor, M. K. \& Cava, F. Genetic Dissection of the Fermentative and Respiratory Contributions Supporting Vibrio cholerae Hypoxic Growth. J Bacteriol 202, doi:10.1128/JB.00243-20 (2020).

5 Bueno, E., Pinedo, V. \& Cava, F. Adaptation of Vibrio cholerae to Hypoxic Environments. Front Microbiol 11, 739, doi:10.3389/fmicb.2020.00739 (2020).

6 Schild, S. et al. Genes induced late in infection increase fitness of Vibrio cholerae after release into the environment. Cell Host Microbe 2, 264-277, doi:10.1016/j.chom.2007.09.004 (2007).

607 Xu, Q., Dziejman, M. \& Mekalanos, J. J. Determination of the transcriptome of Vibrio cholerae during intraintestinal growth and midexponential phase in vitro. 
6118 Mandlik, A. et al. RNA-Seq-based monitoring of infection-linked changes in Vibrio cholerae gene expression. Cell Host Microbe 10, 165-174,

613 doi:10.1016/j.chom.2011.07.007 (2011).

614

9 Beaber, J. W., Hochhut, B. \& Waldor, M. K. SOS response promotes horizontal

615 dissemination of antibiotic resistance genes. Nature 427, 72-74,

616 doi:10.1038/nature02241 (2004).

61710 Narendrakumar, L., Gupta, S. S., Johnson, J. B., Ramamurthy, T. \& Thomas, S. Molecular Adaptations and Antibiotic Resistance in Vibrio cholerae: A Communal Challenge. Microb Drug Resist 25, 1012-1022, doi:10.1089/mdr.2018.0354

620 (2019).

621

11 Das, B., Verma, J., Kumar, P., Ghosh, A. \& Ramamurthy, T. Antibiotic resistance in Vibrio cholerae: Understanding the ecology of resistance genes and mechanisms. Vaccine 38 Suppl 1, A83-A92, doi:10.1016/j.vaccine.2019.06.031 (2020).

62512 The treatment of diarrhoea -- A manual for physicians and other senior health 626 workers. -4th rev. 4th Rev. edn, Vol. WHO/CAH/03.7 (World Heath Organization).

62813 Control, G. T. F. o. C. Cholera outbreak: assessing the outbreak response and 629 improving preparedness. Vol. WHO/CDS/CPE/ZFK/2004.4 (World Health Organization, 2004).

63114 Control., G. T. F. o. C. Use of antibiotics for the treatment and control of cholera, <https://www.who.int/cholera/task_force/use-of-antibiotics-for-the-treatment-ofcholera.pdf?ua=1> (2018). 
63415 Nelson, E. J., Nelson, D. S., Salam, M. A. \& Sack, D. A. Antibiotics for both

635 moderate and severe cholera. N Engl J Med 364, 5-7,

636 doi:10.1056/NEJMp1013771.

63716 Leibovici-Weissman, Y. et al. Antimicrobial drugs for treating cholera. Cochrane Database Syst Rev, CD008625, doi:10.1002/14651858.CD008625.pub2 (2014).

17 Khan, A. I. et al. Electronic decision-support improves diarrhoeal disease guideline adherence (mHealth Diarrhoea Management, mHDM, Trial): a cluster randomized controlled trial. Lancet $\mathrm{DH} 2$, e250-258, doi:https://doi.org/10.1016/S2589-7500(20)30062-5 (2020).

18 Biswas, D. et al. An ethnographic exploration of diarrheal disease management in public hospitals in Bangladesh: From problems to solutions. Soc Sci Med 260, 113185, doi:10.1016/j.socscimed.2020.113185 (2020).

64619 Ingle, D. J., Levine, M. M., Kotloff, K. L., Holt, K. E. \& Robins-Browne, R. M. Dynamics of antimicrobial resistance in intestinal Escherichia coli from children in community settings in South Asia and sub-Saharan Africa. Nat Microbiol 3, 1063-

65020 Weill, F. X. et al. Genomic history of the seventh pandemic of cholera in Africa. 
65622 Burrus, V., Marrero, J. \& Waldor, M. K. The current ICE age: biology and evolution of SXT-related integrating conjugative elements. Plasmid 55, 173-183,

658 doi:S0147-619X(06)00003-5 [pii]

659

10.1016/j.plasmid.2006.01.001 (2006).

660

23 Redgrave, L. S., Sutton, S. B., Webber, M. A. \& Piddock, L. J. Fluoroquinolone

661 resistance: mechanisms, impact on bacteria, and role in evolutionary success.

662 Trends Microbiol 22, 438-445, doi:10.1016/j.tim.2014.04.007 (2014).

663

24 Hooper, D. C. \& Jacoby, G. A. Topoisomerase Inhibitors: Fluoroquinolone 664 Mechanisms of Action and Resistance. Cold Spring Harb Perspect Med 6, doi:10.1101/cshperspect.a025320 (2016).

66625 Piddock, L. J. Mechanisms of fluoroquinolone resistance: an update 1994-1998. Drugs 58 Suppl 2, 11-18, doi:10.2165/00003495-199958002-00003 (1999).

66826 Everett, M. J., Jin, Y. F., Ricci, V. \& Piddock, L. J. Contributions of individual 669 mechanisms to fluoroquinolone resistance in 36 Escherichia coli strains isolated from humans and animals. Antimicrob Agents Chemother 40, 2380-2386,

67227 Komp Lindgren, P., Marcusson, L. L., Sandvang, D., Frimodt-Moller, N. \& Hughes, D. Biological cost of single and multiple norfloxacin resistance mutations in Escherichia coli implicated in urinary tract infections. Antimicrob Agents Chemother 49, 2343-2351, doi:10.1128/AAC.49.6.2343-2351.2005 (2005).

67628 Morgan-Linnell, S. K. \& Zechiedrich, L. Contributions of the combined effects of topoisomerase mutations toward fluoroquinolone resistance in Escherichia coli. 
679

680

681

682

683

684

685

686

687

688

689

690

691

692

693

694

695

696

697

698

699

Antimicrob Agents Chemother 51, 4205-4208, doi:10.1128/AAC.00647-07

(2007).

29 Martinez-Martinez, L., Pascual, A. \& Jacoby, G. A. Quinolone resistance from a transferable plasmid. Lancet 351, 797-799, doi:10.1016/S0140-6736(97)07322-4 (1998).

30 Briales, A. et al. Prevalence of plasmid-mediated quinolone resistance determinants qnr and aac(6')-lb-cr in Escherichia coli and Klebsiella pneumoniae producing extended-spectrum beta-lactamases in Spain. Int J Antimicrob Agents 39, 431-434, doi:10.1016/j.ijantimicag.2011.12.009 (2012).

31 Wozniak, R. A. et al. Comparative ICE genomics: insights into the evolution of the SXT/R391 family of ICEs. PLoS Genet 5, e1000786, doi:10.1371/journal.pgen.1000786 (2009).

32 Beaber, J. W., Hochhut, B. \& Waldor, M. K. Genomic and functional analyses of SXT, an integrating antibiotic resistance gene transfer element derived from Vibrio cholerae. J Bacteriol 184, 4259-4269, doi:10.1128/jb.184.15.42594269.2002 (2002).

33 Garriss, G., Waldor, M. K. \& Burrus, V. Mobile antibiotic resistance encoding elements promote their own diversity. PLoS Genet 5, e1000775, doi:10.1371/journal.pgen.1000775 (2009).

34 Fonseca, E. L., Dos Santos Freitas, F., Vieira, V. V. \& Vicente, A. C. New qnr gene cassettes associated with superintegron repeats in Vibrio cholerae 01. Emerg Infect Dis 14, 1129-1131, doi:10.3201/eid1407.080132 (2008). 
70035 Fyfe, C., Grossman, T. H., Kerstein, K. \& Sutcliffe, J. Resistance to Macrolide Antibiotics in Public Health Pathogens. Cold Spring Harb Perspect Med 6, doi:10.1101/cshperspect.a025395 (2016).

70336 Grossman, T. H. Tetracycline Antibiotics and Resistance. Cold Spring Harb

704 Perspect Med 6, a025387, doi:10.1101/cshperspect.a025387 (2016).

70537 Zhu, Z. et al. Entropy of a bacterial stress response is a generalizable predictor 706 for fitness and antibiotic sensitivity. Nat Commun 11, 4365, doi:10.1038/s41467020-18134-z (2020).

708

709

710

711

38 Wood, S. et al. in The Pangenome: Diversity, Dynamics and Evolution of Genomes (eds H. Tettelin \& D. Medini) 169-202 (2020).

39 Warrier, I. et al. The Transcriptional landscape of Streptococcus pneumoniae TIGR4 reveals a complex operon architecture and abundant riboregulation critical for growth and virulence. PLoS Pathog 14, e1007461, doi:10.1371/journal.ppat.1007461 (2018).

Jensen, P. A., Zhu, Z. \& van Opijnen, T. Antibiotics Disrupt Coordination between Transcriptional and Phenotypic Stress Responses in Pathogenic Bacteria. Cell Rep 20, 1705-1716, doi:10.1016/j.celrep.2017.07.062 (2017).

41 van Opijnen, T., Dedrick, S. \& Bento, J. Strain Dependent Genetic Networks for Antibiotic-Sensitivity in a Bacterial Pathogen with a Large Pan-Genome. PLoS Pathog 12, e1005869, doi:10.1371/journal.ppat.1005869 (2016). Cain, A. K. et al. A decade of advances in transposon-insertion sequencing. Nat Rev Genet 21, 526-540, doi:10.1038/s41576-020-0244-x (2020). 
72243 Dorr, T. et al. A Transposon Screen Identifies Genetic Determinants of Vibrio cholerae Resistance to High-Molecular-Weight Antibiotics. Antimicrob Agents Chemother 60, 4757-4763, doi:10.1128/AAC.00576-16 (2016).

725

726

727

728

729

730

731

732

733

734

735

736

737

738

739

740

741

742

743

44 Kohanski, M. A., Dwyer, D. J., Hayete, B., Lawrence, C. A. \& Collins, J. J. A common mechanism of cellular death induced by bactericidal antibiotics. Cell 130, 797-810, doi:10.1016/j.cell.2007.06.049 (2007).

45 Maslowska, K. H., Makiela-Dzbenska, K. \& Fijalkowska, I. J. The SOS system: A complex and tightly regulated response to DNA damage. Environ Mol Mutagen 60, 368-384, doi:10.1002/em.22267 (2019).

46 Dwyer, D. J. et al. Antibiotics induce redox-related physiological alterations as part of their lethality. Proc Natl Acad Sci U S A 111, E2100-2109, doi:10.1073/pnas.1401876111 (2014).

47 Staerck, C. et al. Microbial antioxidant defense enzymes. Microb Pathog 110, 5665, doi:10.1016/j.micpath.2017.06.015 (2017).

48 Smirnova, G., Muzyka, N. \& Oktyabrsky, O. Transmembrane glutathione cycling in growing Escherichia coli cells. Microbiol Res 167, 166-172, doi:10.1016/j.micres.2011.05.005 (2012).

49 Bryan, L. E. \& Kwan, S. Mechanisms of aminoglycoside resistance of anaerobic bacteria and facultative bacteria grown anaerobically. J Antimicrob Chemother 8 Suppl D, 1-8, doi:10.1093/jac/8.suppl_d.1 (1981).

50 Bryan, L. E. General mechanisms of resistance to antibiotics. J Antimicrob Chemother 22 Suppl A, 1-15, doi:10.1093/jac/22.supplement_a.1 (1988). 
$74451 \quad$ Bryant, R. E., Fox, K., Oh, G. \& Morthland, V. H. Beta-lactam enhancement of

745

746

747

748

749

750

751

752

753

754

755

756

757

758

759

760

761

762

763

764

765 aminoglycoside activity under conditions of reduced $\mathrm{pH}$ and oxygen tension that may exist in infected tissues. $J$ Infect Dis 165, 676-682, doi:10.1093/infdis/165.4.676 (1992).

52 Dwyer, D. J., Kohanski, M. A., Hayete, B. \& Collins, J. J. Gyrase inhibitors induce an oxidative damage cellular death pathway in Escherichia coli. Mol Syst Biol 3, 91, doi:10.1038/msb4100135 (2007).

53 Drlica, K. \& Zhao, X. Bacterial death from treatment with fluoroquinolones and other lethal stressors. Expert Rev Anti Infect Ther, 1-18, doi:10.1080/14787210.2021.1840353 (2020).

54 Hong, Y. et al. Reactive oxygen species play a dominant role in all pathways of rapid quinolone-mediated killing. J Antimicrob Chemother 75, 576-585, doi:10.1093/jac/dkz485 (2020).

55 Luan, G., Hong, Y., Drlica, K. \& Zhao, X. Suppression of Reactive Oxygen Species Accumulation Accounts for Paradoxical Bacterial Survival at High Quinolone Concentration. Antimicrob Agents Chemother 62, doi:10.1128/AAC.01622-17 (2018).

56 Zhao, X. \& Drlica, K. Reactive oxygen species and the bacterial response to lethal stress. Curr Opin Microbiol 21, 1-6, doi:10.1016/j.mib.2014.06.008 (2014).

57 Zhao, X., Hong, Y. \& Drlica, K. Moving forward with reactive oxygen species involvement in antimicrobial lethality. J Antimicrob Chemother 70, 639-642, doi:10.1093/jac/dku463 (2015). 
$76658 \quad$ Nelson, E. J. et al. Complexity of rice-water stool from patients with Vibrio

767

768

769

770

771

772

773

774

775

776

777

778

779

780

781

782

783

784

785

786

787 cholerae plays a role in the transmission of infectious diarrhea. Proc Natl Acad Sci U S A 104, 19091-19096, doi:0706352104 [pii]

10.1073/pnas.0706352104 (2007).

59 Sprouffske, K. \& Wagner, A. Growthcurver: an R package for obtaining interpretable metrics from microbial growth curves. BMC Bioinformatics 17, 172, doi:10.1186/s12859-016-1016-7 (2016).

60 Jia, B. et al. CARD 2017: expansion and model-centric curation of the comprehensive antibiotic resistance database. Nucleic Acids Res 45, D566D573, doi:10.1093/nar/gkw1004 (2017).

61 McArthur, A. G. et al. The comprehensive antibiotic resistance database. Antimicrob Agents Chemother 57, 3348-3357, doi:10.1128/AAC.00419-13 (2013).

62 Zankari, E. Comparison of the web tools ARG-ANNOT and ResFinder for detection of resistance genes in bacteria. Antimicrob Agents Chemother 58, 4986, doi:10.1128/AAC.02620-14 (2014).

63 Kleinheinz, K. A., Joensen, K. G. \& Larsen, M. V. Applying the ResFinder and VirulenceFinder web-services for easy identification of acquired antibiotic resistance and $\mathrm{E}$. coli virulence genes in bacteriophage and prophage nucleotide sequences. Bacteriophage 4, e27943, doi:10.4161/bact.27943 (2014).

64 Drezen, E. et al. GATB: Genome Assembly \& Analysis Tool Box. Bioinformatics 30, 2959-2961, doi:10.1093/bioinformatics/btu406 (2014). 
788

789

790

791

792

793

794

795

796

797

798

799

800

801

802

803

804

805

806

807

808

809

810

65 Lees, J. A., Galardini, M., Bentley, S. D., Weiser, J. N. \& Corander, J. pyseer: a comprehensive tool for microbial pangenome-wide association studies.

Bioinformatics 34, 4310-4312, doi:10.1093/bioinformatics/bty539 (2018).

66 Cook, D. E. \& Andersen, E. C. VCF-kit: assorted utilities for the variant call format. Bioinformatics 33, 1581-1582, doi:10.1093/bioinformatics/btx011 (2017).

67 Stamatakis, A. RAxML version 8: a tool for phylogenetic analysis and postanalysis of large phylogenies. Bioinformatics 30, 1312-1313, doi:10.1093/bioinformatics/btu033 (2014).

68 Saber, M. M. \& Shapiro, B. J. Benchmarking bacterial genome-wide association study methods using simulated genomes and phenotypes. Microb Genom 6, doi:10.1099/mgen.0.000337 (2020).

69 Alexandrova, L. et al. Identification of widespread antibiotic exposure in cholera patients correlates with clinically relevant microbiota changes. J Infect Dis, doi:10.1093/infdis/jiz299 (2019).

70 Davydova, N., Streltsov, V., Wilce, M., Liljas, A. \& Garber, M. L22 ribosomal protein and effect of its mutation on ribosome resistance to erythromycin. $J \mathrm{Mol}$ Biol 322, 635-644, doi:10.1016/s0022-2836(02)00772-6 (2002).

71 Hansen, L. H., Mauvais, P. \& Douthwaite, S. The macrolide-ketolide antibiotic binding site is formed by structures in domains II and V of $23 S$ ribosomal RNA. Mol Microbio/ 31, 623-631, doi:10.1046/j.1365-2958.1999.01202.x (1999).

72 Williams, G. \& Smith, I. Chromosomal mutations causing resistance to tetracycline in Bacillus subtilis. Mol Gen Genet 177, 23-29, doi:10.1007/BF00267249 (1979). 
81173 Wei, Y. \& Bechhofer, D. H. Tetracycline induces stabilization of mRNA in Bacillus subtilis. J Bacteriol 184, 889-894, doi:10.1128/jb.184.4.889-894.2002 (2002).

81374 Beabout, K. et al. The ribosomal S10 protein is a general target for decreased tigecycline susceptibility. Antimicrob Agents Chemother 59, 5561-5566,

815 doi:10.1128/AAC.00547-15 (2015).

81675 Leclercq, S. O. et al. Diversity of the Tetracycline Mobilome within a Chinese Pig Manure Sample. Appl Environ Microbiol 82, 6454-6462, doi:10.1128/AEM.0175416 (2016).

81976 Grossman, T. H. et al. Target- and resistance-based mechanistic studies with TP-434, a novel fluorocycline antibiotic. Antimicrob Agents Chemother 56, 25592564, doi:10.1128/AAC.06187-11 (2012).

82277 Noguchi, N. et al. Nucleotide sequence and characterization of erythromycin resistance determinant that encodes macrolide 2'-phosphotransferase I in Escherichia coli. Antimicrob Agents Chemother 39, 2359-2363, doi:10.1128/AAC.39.10.2359 (1995).

82678 Chesneau, O., Tsvetkova, K. \& Courvalin, P. Resistance phenotypes conferred by macrolide phosphotransferases. FEMS Microbiol Lett 269, 317-322, doi:10.1111/j.1574-6968.2007.00643.x (2007).

82979 Mathur, J. \& Waldor, M. K. The Vibrio cholerae ToxR-regulated porin OmpU confers resistance to antimicrobial peptides. Infect Immun 72, 3577-3583, doi:10.1128/IAI.72.6.3577-3583.2004 (2004). 
83280 Li, C. C., Crawford, J. A., DiRita, V. J. \& Kaper, J. B. Molecular cloning and transcriptional regulation of ompT, a ToxR-repressed gene in Vibrio cholerae. Mol Microbiol 35, 189-203, doi:10.1046/j.1365-2958.2000.01699.x (2000).

835

836

837

838

839

840

841

842

843

844

845

846

847

848

849

850

851

852

853

854

81 Buckley, A. M. et al. The AcrAB-TolC efflux system of Salmonella enterica serovar Typhimurium plays a role in pathogenesis. Cell Microbiol 8, 847-856, doi:10.1111/j.1462-5822.2005.00671.x (2006).

82 Taylor, D. L., Bina, X. R. \& Bina, J. E. Vibrio cholerae VexH encodes a multiple drug efflux pump that contributes to the production of cholera toxin and the toxin co-regulated pilus. PLoS One 7, e38208, doi:10.1371/journal.pone.0038208 (2012).

83 Bina, X. R., Philippart, J. A. \& Bina, J. E. Effect of the efflux inhibitors 1-(1naphthylmethyl)-piperazine and phenyl-arginine-beta-naphthylamide on antimicrobial susceptibility and virulence factor production in Vibrio cholerae. $J$ Antimicrob Chemother 63, 103-108, doi:10.1093/jac/dkn466 (2009).

84 Doron, S. et al. Systematic discovery of antiphage defense systems in the microbial pangenome. Science 359, doi:10.1126/science.aar4120 (2018).

85 Baddam, R. et al. Genome Dynamics of Vibrio cholerae Isolates Linked to Seasonal Outbreaks of Cholera in Dhaka, Bangladesh. mBio 11, doi:10.1128/mBio.03339-19 (2020).

86 Murphy, S. G., Johnson, B. A., Ledoux, C. M. \& Dörr, T. <em>Vibrio cholerae</em>'s mysterious Seventh Pandemic island (VSP-II) encodes novel Zur-regulated zinc starvation genes involved in chemotaxis and autoaggregation. bioRxiv, 2021.2003.2009.434465, doi:10.1101/2021.03.09.434465 (2021). 
bioRxiv preprint doi: https://doi org/10.1101/2021.06.26.450051; this version posted June 27, 2021. The copyright holder for this preprint (which was not certified by peer review) is the author/funder, who has granted bioRxiv a license to display the preprint in perpetuity. It is made available under aCC-BY-NC-ND 4.0 International license.

85587 Angeles, L. F. et al. Retrospective suspect screening reveals previously ignored

856 antibiotics, antifungal compounds, and metabolites in Bangladesh surface

857 waters. Sci Total Environ 712, 136285, doi:10.1016/j.scitotenv.2019.136285

858 (2020).

859 